Article

\title{
In Silico Analysis of Fungal and Chloride-Dependent $\alpha$-Amylases within the Family GH13 with Identification of Possible Secondary Surface-Binding Sites
}

\author{
Zuzana Janíčková ${ }^{1,2}$ and Štefan Janeček ${ }^{1,2, * \mathbb{D}}$ \\ 1 Department of Biology, Faculty of Natural Sciences, University of Ss. Cyril and Methodius, \\ SK-91701 Trnava, Slovakia; zuzana.janickova1@gmail.com \\ 2 Laboratory of Protein Evolution, Institute of Molecular Biology, Slovak Academy of Sciences, \\ SK-84551 Bratislava, Slovakia \\ * Correspondence: Stefan.Janecek@savba.sk
}

Citation: Janíčková, Z.; Janeček, Š. In Silico Analysis of Fungal and Chloride-Dependent $\alpha$-Amylases within the Family GH13 with Identification of Possible Secondary Surface-Binding Sites. Molecules 2021, 26, 5704. https://doi.org/10.3390/ molecules 26185704

Academic Editor: Paolo Iadarola

Received: 2 August 2021

Accepted: 15 September 2021

Published: 21 September 2021

Publisher's Note: MDPI stays neutral with regard to jurisdictional claims in published maps and institutional affiliations.

Copyright: (c) 2021 by the authors. Licensee MDPI, Basel, Switzerland. This article is an open access article distributed under the terms and conditions of the Creative Commons Attribution (CC BY) license (https:// creativecommons.org/licenses/by/ $4.0 /)$.

\begin{abstract}
This study brings a detailed bioinformatics analysis of fungal and chloride-dependent $\alpha$-amylases from the family GH13. Overall, $268 \alpha$-amylase sequences were retrieved from subfamilies GH13_1 (39 sequences), GH13_5 (35 sequences), GH13_15 (28 sequences), GH13_24 (23 sequences), GH13_32 (140 sequences) and GH13_42 (3 sequences). Eight conserved sequence regions (CSRs) characteristic for the family GH13 were identified in all sequences and respective sequence logos were analysed in an effort to identify unique sequence features of each subfamily. The main emphasis was given on the subfamily GH13_32 since it contains both fungal $\alpha$-amylases and their bacterial chloride-activated counterparts. In addition to in silico analysis focused on eventual ability to bind the chloride anion, the property typical mainly for animal $\alpha$-amylases from subfamilies GH13_15 and GH13_24, attention has been paid also to the potential presence of the so-called secondary surface-binding sites (SBSs) identified in complexed crystal structures of some particular $\alpha$-amylases from the studied subfamilies. As template enzymes with already experimentally determined SBSs, the $\alpha$-amylases from Aspergillus niger (GH13_1), Bacillus halmapalus, Bacillus paralicheniformis and Halothermothrix orenii (all from GH13_5) and Homo sapiens (saliva; GH13_24) were used. Evolutionary relationships between GH13 fungal and chloride-dependent $\alpha$-amylases were demonstrated by two evolutionary trees-one based on the alignment of the segment of sequences spanning almost the entire catalytic TIM-barrel domain and the other one based on the alignment of eight extracted CSRs. Although both trees demonstrated similar results in terms of a closer evolutionary relatedness of subfamilies GH13_1 with GH13_42 including in a wider sense also the subfamily GH13_5 as well as for subfamilies GH13_32, GH13_15 and GH13_24, some subtle differences in clustering of particular $\alpha$-amylases may nevertheless be observed.
\end{abstract}

Keywords: $\alpha$-amylase family GH13; fungal $\alpha$-amylases; chloride-dependent $\alpha$-amylases; GH13 subfamilies; surface-binding sites; unique sequence features; evolutionary relationships

\section{Introduction}

$\alpha$-Amylase (EC 3.2.1.1) is a starch hydrolase catalysing the hydrolysis of $\alpha$-1,4-glycosidic linkages in starch, glycogen and related $\alpha$-glucans into maltooligosaccharides that, depending on the source of the enzyme, may vary in their actual lengths [1]. Since $\alpha$-amylases are produced by most organisms from Bacteria, Archaea and Eucarya [1-5], due to genome sequencing projects, thousands of their sequences have become available in the sequencebased classification of carbohydrate-active enzymes, i.e., the CAZy database [6]. Interestingly, the $\alpha$-amylase enzyme specificity is obviously present in more glycoside hydrolase (GH) families: (i) the main and the largest $\alpha$-amylase family GH13 forming with families GH70 and GH77 the clan GH-H; (ii) the second and the smaller $\alpha$-amylase family GH57 
exhibiting a relatedness with the little family GH119; and (iii) eventually also the family GH126 [1,6-10].

The $\alpha$-amylase family GH13 belongs to the largest GH families within the entire Carbohydrate-Active enZymes (CAZy) database; the number of sequences, at the September 2021 update, being more than 120 thousand members ([6]; http://www.cazy.org/ GH13.html (accessed on 10 September 2021)). The family, however, is a polyspecific one, i.e., in addition to $\alpha$-amylase, it covers also pullulanase, isoamylase, cyclodextrin glucanotransferase, glucan branching and debranching enzymes and others whose number has already exceeded 30 different enzyme specificities [1,6,7,11-15]. All GH13 members exhibit several exclusive characteristics, such as the presence of a TIM-barrel catalytic domain with 4-7 seven conserved sequence regions (CSRs), sharing the catalytic machinery of Asp (at the strand $\beta 4$ ), Glu ( $\beta 5)$ and Asp ( $\beta 7)$ as the catalytic nucleophile, proton donor and transition-state stabilizer, respectively, and employing the retaining reaction mechanism $[1,7,12-18]$. Although some sequentially closely related groups of enzymes were suggested to define the subfamilies of oligo-1,6-glucosidase and neopullulanase with an intermediary group in 2002 [19], the entire family has been officially divided into 35 GH13 subfamilies by CAZy curators in 2006 [20]. Currently, there are 44 GH13 subfamilies [6,21]; their number is expected to rise even further in the future [22,23].

Of the 44 GH13 subfamilies, 15 can be considered as those comprising the $\alpha$-amylase enzyme specificity: GH13_1, 5, 6, 7, 15, 19, 24, 27, 28, 32, 36, 37, 41, 42 and 43 [1,6,7,20,21]. Some of them reflect also taxonomic differences known from the time when the family was originally established [1,7]. Thus, for example: (i) subfamilies GH13_1, 6, 7, 15 and 24 have long time been recognized as those containing typical fungal, plant, archaeal, insect and animal $\alpha$-amylases, respectively; (ii) subfamilies GH13_5 and 28, have both been treated as bacterial ones comprising, respectively, liquefying and saccharifying $\alpha$-amylases from bacilli; and (iii) with regard to subfamilies GH13_32 and 36, the former has originally been reserved for $\alpha$-amylases from actinobacteria closely related to animal counterparts, whereas the latter has been devoted to the so-called intermediary group of $\alpha$-amylases with the extended enzyme specificity including the activity to cyclodextrins [24-27].

Most of the above-mentioned GH13 subfamilies have later expanded, e.g., both typical plant and archaeal $\alpha$-amylase subfamilies GH13_6 and 7 contain today also various bacterial homologues [6,7] and fungal $\alpha$-amylases have recently been found in four GH13 subfamilies, i.e., in addition to the subfamily GH13_1, they have also been classified in subfamilies GH13_5, 32 and even 42 [6,28-30]. In this respect, the presence of fungal $\alpha$-amylases in the subfamily GH13_32, revealed originally in 2013 [29], is of a special interest because this subfamily has been best known as that grouping the $\alpha$-amylases from Actinomycetes, which exhibit close sequence-structural similarities with $\alpha$-amylases from insects (GH13_15) and animals (GH13_24) [21,25,26]. Moreover, the most deeply studied member of the subfamily GH13_32, the $\alpha$-amylase from Pseudoalteromonas haloplanktis [31], which was revealed to resemble closely even the $\alpha$-amylases from mammals [24,32]. The resemblance has later been confirmed also with regard to binding chloride anion [33-35], the feature otherwise typical for insect and animal $\alpha$-amylases from both subfamilies GH13_15 and 24 [36-42].

The second characteristic feature of $\alpha$-amylases that has attracted a significant interest is represented by the presence of some secondary surface-binding sites (SBSs) situated on the catalytic TIM-barrel domain [43]. These SBSs are different from those located within a distinct starch-binding domain (SBD), which exists separately from the catalytic domain and have been classified as carbohydrate-binding module (CBM) families [6,44]. They should improve the substrate adsorption, but in contrast to SBDs, they are not easily recognized at the sequence level [43-48]. The SBSs have thus been revealed in three-dimensional structures solved as complexes with various ligands in several $\alpha$-amylases, e.g., Aspergillus niger from the subfamily GH13_1 [49], Bacillus halmapalus, Bacillus paralicheniformis and Halothermothrix orenii (AmyB) from the subfamily GH13_5 [50-52], and pig (pancreas) and human (saliva) from the subfamily GH13_24 [53,54]. 
This study therefore delivers the in silico analysis of $268 \alpha$-amylase sequences from subfamilies GH13_1, 5, 15, 24, 32 and 42. It was based on the above-mentioned phenomenon of close relatedness of bacterial $\alpha$-amylases from Actinomycetes from the subfamily GH13_32 with their animal counterparts from insects and mammals from subfamilies GH13_15 and GH13_24, respectively, which are chloride-activated, i.e., chloride-dependent $\alpha$-amylases. Since the dependence on chloride anion has already been confirmed for some bacterial $\alpha$-amylases in the subfamily GH13_32, it would be interested to investigate whether or not also the fungal $\alpha$-amylases classified in this subfamily may require the chloride for their proper functioning. In addition to this main goal of the present study, a detailed sequence-structural comparison with respect to the eventual presence of SBSs within the entire set of 268 studied sequences of $\alpha$-amylases has also been performed.

\section{Results and Discussion}

The present in silico study is a continuation of the previous bioinformatics analysis delivering an exhaustive comparison of 522 sequences of $\alpha$-amylase mostly of fungal origin classified in three subfamilies GH13_1, GH13_5 and GH13_32 [30]. Here, in addition to the three GH13 fungal subfamilies mentioned above, also $\alpha$-amylase sequences from the family GH13_42 were included. However, since the subfamily GH13_32 covers also the so-called animal-like $\alpha$-amylases from actinobacteria [29], the two GH13 subfamilies with typical chloride-activated animal $\alpha$-amylases, GH13_15 and GH13_24 [24,26,33,35], were taken into the comparison. Overall, $268 \alpha$-amylase sequences were thus studied (Table 1).

Table 1. Summary of 268 fungal and chloride-dependent $\alpha$-amylases from the family GH13 used in the present study ${ }^{1}$.

\begin{tabular}{cccccccccccccc}
\hline Subfamily & \multicolumn{2}{c}{ GH13_1 } & \multicolumn{2}{c}{ GH13_5 } & \multicolumn{2}{c}{ GH13_15 } & \multicolumn{2}{c}{ GH13_24 } & \multicolumn{3}{c}{ GH13_32 } & GH13_42 \\
\hline & P & E & P & E & P & E & P & E & P & E & P & E \\
\hline Total & 2 & 37 & 32 & 3 & 0 & 28 & 0 & 23 & 20 & 120 & 2 \\
\hline
\end{tabular}

${ }^{1}$ The set was created based on sequences classified in the CAZy family GH13 completed by $\alpha$-amylases obtained by BLAST searches. The "P" and "E" mean Procarya and Eucarya, respectively.

\subsection{Sequence Logos of $\alpha$-Amylases from Different GH13 Subfamilies}

In all 268 collected sequences (Table S1), seven CSRs characteristic for the $\alpha$-amylase family GH13 $[1,18]$ were identified along with the eighth CSR located around the strand $\beta 1$ of the catalytic TIM-barrel [24]. Overall, seven sequence logos were constructed (Figure 1), i.e., the first one for all 268 studied sequences, whereas the remaining six logos were prepared for individual subfamilies GH13_1, GH13_5, GH13_15, GH13_24, GH13_32 and GH13_42. Each logo was calculated based on the alignment of all eight CSRs extracted from the alignment of all $268 \alpha$-amylase sequences that spanned the sequence segment from the beginning of the strand $\beta 1$ (CSR-VIII) to the end of the strand $\beta 8$ (CSR-VII) of the catalytic TIM-barrel domain including the entire domain B (Figure S1).

It is clearly obvious that each GH13 subfamily retains its unique sequence features discriminating the subfamilies from each other (Figure 1). In addition to catalytic machinery, i.e., positions 28 (Asp, catalytic nucleophile), 37 (Glu, catalytic proton donor) and 46 (Asp, transition-state stabilizer), the sequence logo contains also the residues involved in binding the chloride anion by animal and animal-like $\alpha$-amylases from subfamilies GH13_15, GH13_24 and also GH13_32 (Figure 1)—positions 26 (arginine), 44 (asparagine) and 50 (arginine/lysine) [33-42]. 
A

All subfamilies (268 sequences)

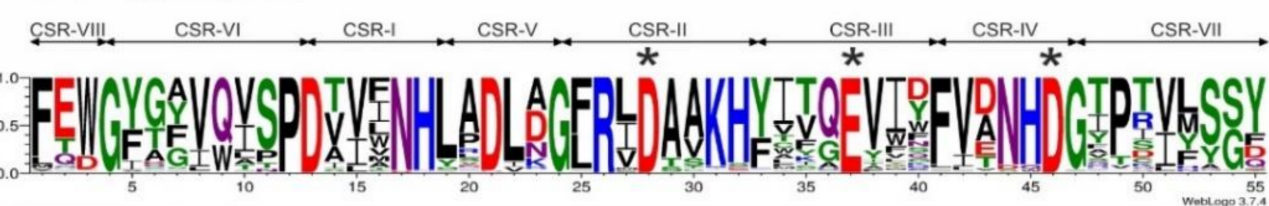

B

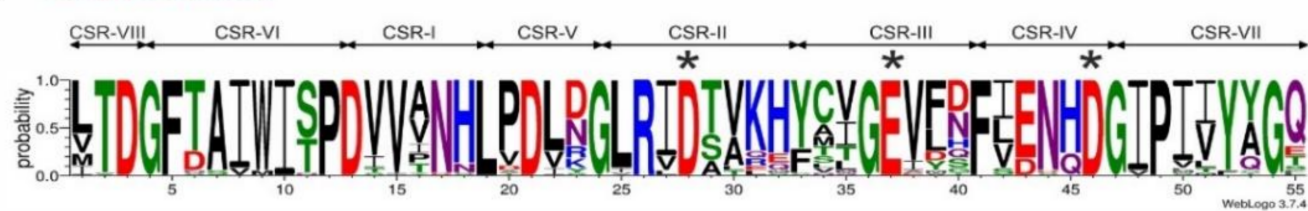

C

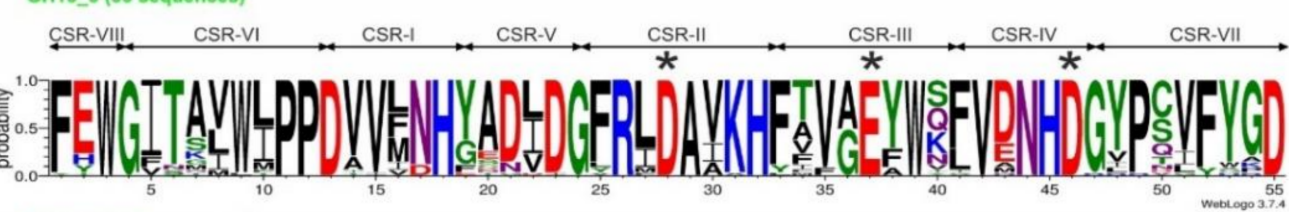

D GH13_15 (28 sequences)

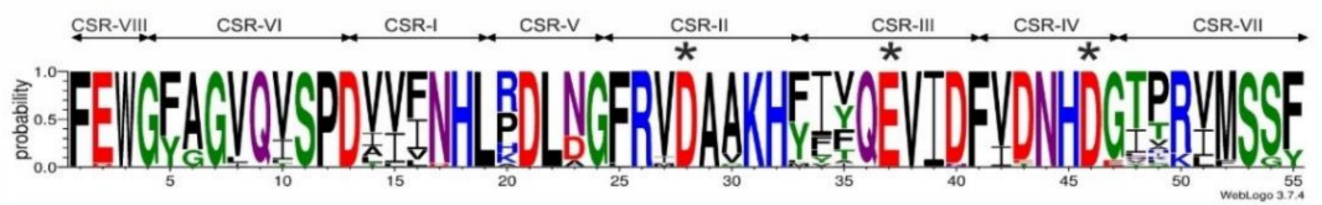

E GH13_24(23 sequences)

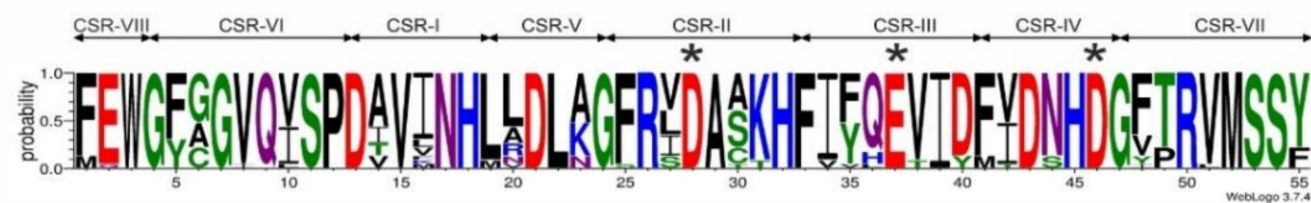

F GH13_32 (140 sequences)

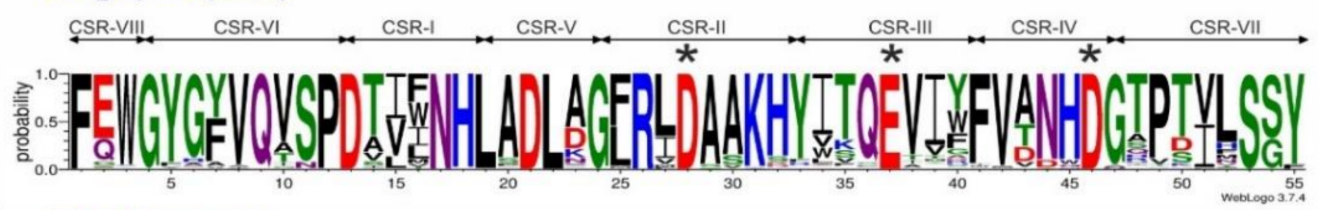

G

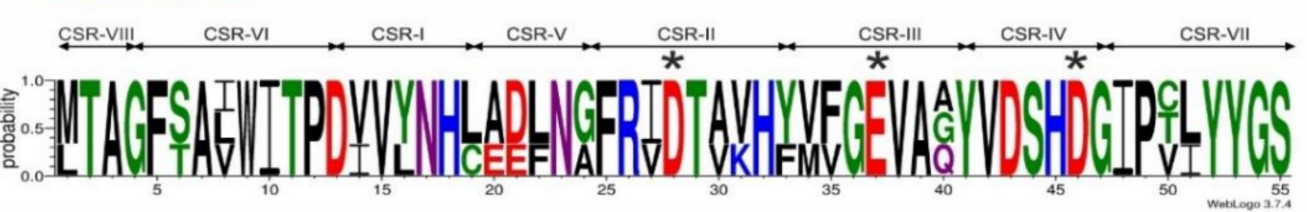

Figure 1. Sequence logos of $\alpha$-amylases from studied GH13 subfamilies. Logos for (A) all the six studied subfamilies (268 sequences); (B) subfamily GH13_1 (39 sequences); (C) subfamily GH13_5 (35 sequences); (D) G13_15 (28 sequences); (E) subfamily GH13_24 (23 sequences); (F) subfamily GH13_32 (140 sequences); and (G) G13_42 (3 sequences). CSR-I, residues 13-18; CSR-II, residues 24-32; CSR-III, residues 33-40; CSR-IV, residues 41-46; CSR-V, residues 19-23; CSR-VI, residues 4-12; CSR-VII, residues 47-55; CSR-VIII, residues 1-3. The catalytic triad, i.e., the catalytic nucleophile (No. 28, aspartic acid in CSR-II), the proton donor (No. 37, glutamic acid in CSR-III) and the transition-state stabilizer (No. 46, aspartic acid in CSR-IV) are indicated by asterisks.

The unique features within the sequence logo for the three fungal GH13 subfamilies GH13_1, GH13_5 and GH13_32 as well as those shared by two of the three subfamilies have already been described in a detail recently [30]. Here, also the subfamily GH13_42, although it currently contains only one putative fungal $\alpha$-amylase [6], has been added. It is evident that it also exhibits its own unique sequence features, such as positions 1-3 (CSR-VIII) occupied by residues mTA and positions 53-56 (CSR-VII) with the motif YYGS. 
Single positions, i.e., threonine, tyrosine and eventually also serine in positions 11,41 and 44 , respectively, may be of interest since these positions in the counterpart $\alpha$-amylases from other GH13 subfamilies are occupied by different residues (Figure 1). It should be pointed out, however, the importance of the logo for the subfamily GH13_42 is still limited because it was based on 3 sequences only-one putative fungal $\alpha$-amylase and two characterized members from bacteria [6] (cf. Table 1).

\subsection{Analysis of Chloride Anion Binding}

The chloride anion, which is necessary for allosteric activation of mainly animal (mammalian) $\alpha$-amylases [36-41], is co-ordinated by side-chains of two arginines and one asparagine (the second arginine being substituted by a lysine) that correspond to Arg196, Asn286 and Lys324 in the GH13_32 $\alpha$-amylase from Pseudoalteromonas haloplanktis [33-35]. Overall, the substitution of the second arginine by a lysine should, however, in no case eliminate the ability of an $\alpha$-amylase to bind the chloride anion, since the lysine is, similar to arginine, also positively charged [42].

All these three residues have been in this study identified only in members of subfamilies GH13_15 and GH13_24 as well as in some bacterial $\alpha$-amylases from the subfamily GH13-32 (Figure S1). The arginine (Arg196 above) - located in the CSR-II (strand $\beta 4$; in position $i$-2 with regard to catalytic nucleophile) - is present in all $268 \alpha$-amylases studied here; it represents, in fact, the fourth most invariant residue within the entire family GH13, in addition to the catalytic triad [18]. Concerning the two other residues (Asn286 and Lys324), the asparagine positioned in the CSR-IV (strand $\beta 7$ ) three residues before the transition state stabilizer-like the above-mentioned arginine-also belongs to most highly conserved residues in the $\alpha$-amylase family GH13 [7,14]. Interestingly, aside the typical fungal subfamily GH13_1, this residue is also not invariantly conserved even in the animal $\alpha$-amylase subfamily GH13_24 (Figure S1), for members of which the activation by chloride anion has been well documented [42]. This asparagine is replaced by a serine in mites from Acarus siro ([55]; GenBank: ABL09312.1), Dermatophagoides pteronyssinus ([56]; AAD38942.1) and Euroglyphus maynei ([56]; AAD38943.1). The third residue involved in chloride binding, which is_for animal $\alpha$-amylases_typically arginine (Arg321 and Arg337 in GH13_15 Tenebrio molitor and GH13_24 human salivary $\alpha$-amylases, respectively $[39,40])$-is located in the CSR-VII (strand $\beta 8$ ). It is conserved invariantly in GH13_24, almost invariantly in GH13_15, where in the latter it is substituted by a lysine in four cases: Anthonomus grandis ([57]; AAN77138.1 and AAN77139.1), Callosobruchus chinensis ([58]; BAB72257.1) and Zabrotes subfasciatus ([59]; AAF73435.1). It is worth mentioning that in the subfamily GH13_32, it is present only as a lysine and only in a few bacterial cases: Halomonas meridiana ([60]; CAB92963.1), Pseudoalteromonas haloplanktis ([31]; CAA41481.1), Pseudomonas sp. KFCC10818 ([61]; AAA86835.1), Thermobifida fusca ([62]; ABF13430.1) and Thermomonospora curvata ([63]; CAA41881.1), because none of GH13_32 $\alpha$-amylase of fungal origin possesses it (Figure S1). Finally, in remaining $\alpha$-amylase subfamilies from this analysis_-GH13_1, GH13_5 and GH13_42-neither arginine, nor lysine is found in the position corresponding with this arginine from the CSR-VII. Based on these observations, it is most probable that fungal $\alpha$-amylases from any GH13 subfamily (1, 5, 32 and even 42) are not able to bind the chloride, and thus, they cannot be activated by this anion.

\subsection{Analysis of Surface Binding Sites}

The secondary SBSs represent a binding site for a ligand, located outside the active site of the enzyme [43-48]. If the entire family GH13 is considered, no special conserving of any amino acid residue involved in an SBS has been observed [49-54]. However, within the individual GH13 subfamilies, the preservation may obviously be higher (Figure S1).

As far as the GH13 subfamilies of the present study are concerned, the SBSs were identified in three-dimensional structures of only three of them-GH13_1, GH13_5 and GH13_24. In the subfamily GH13_1, one SBS was revealed in the $\alpha$-amylase from Aspergillus niger formed by residues Tyr382 and Trp385 [49]. In the subfamily GH13_5, SBSs were found 
in three $\alpha$-amylases: (i) the $\alpha$-amylase from Bacillus halmapalus possessing three SBSs: SBSI—residues Trp439 and Trp469, SBS-II—residue Trp347, and SBS-III—residue Tyr363 [50]; (ii) $\alpha$-amylase from Bacillus licheniformis (known also as Bacillus paralichenifromis) having one SBS formed by residues Phe257 and Tyr358 [51]; and (iii) the $\alpha$-amylase AmyB from Halothermothrix orenii with three SBSs: SBS-I-residues Tyr460 and Trp488, SBS-II-residues Trp260 and Trp287, and SBS-III - residues Trp306 and W310 [52]. Finally, in the subfamily GH13_24, in addition to two SBSs seen in the $\alpha$-amylase from pig pancreas [53], four SBSs were demonstrated in the $\alpha$-amylase from human saliva [54] as follows: SBS-I-residues Tyr276 and Trp284, SBS-II—residues Trp316 and Trp388, SBS-III—residue Trp203, and SBS-IV—residue Trp134.

The residues involved in the above-mentioned experimentally identified SBSs were checked for their correspondences within the particular subfamilies (Figure S1), especially if they are replaced by non-aromatic residues. Thus, in the subfamily GH13_1, both SBS residues Tyr382 and Trp385 of the $\alpha$-amylase from Aspergillus niger [49] were found as conserved in counterpart $\alpha$-amylases from (Table 2) Aspergillus awamori ([64]; GenBank: BAD06002.1), Aspergillus flavus ([65]; AAF14264.1), Aspergillus kawachii ([66]; BAD01051.1), Aspergillus oryzae ([67]; CAA31218.1), Aspergillus shirousami ([68]; BAA01255.1), Fusicoccum sp. BCC4124 ([69]; ABG48762.1), Lipomyces spencermartinsiae ([70]; AAC49622.1) and Lipomyces starkeyi ([71]; AAN75021.1). As two aromatic positions, it even might be preserved in other $\alpha$-amylases, e.g., from Sclerotinia sclerotiorum ([72]; ACN82436.1). On the other hand, the $\alpha$-amylase from Saccharomycopsis fibuligera able to degrade raw starch [73] obviously does not possess the corresponding SBS (Table 2). It is of note that in the recently solved three-dimensional structure of the GH13_1 $\alpha$-amylase from Cordyceps farinosa [74] an SBS was identified in domain $C$ with modelled maltose and only one aromatic residuePhe387-involved in binding. It, however, corresponds with neither of the two aromatic residues forming the SBS-I of the GH13_1 A. niger counterpart (Table 2). Interestingly, when the domain $C$ of $C$. farinosa $\alpha$-amylase was superimposed with the CBM20 of GH15 glucoamylase from Aspergillus niger [75], its SBS was seen in a close proximity with the binding site of the CBM20 from the glucoamylase [74].

Table 2. Residues corresponding with the SBS from $A$. niger $\alpha$-amylase ${ }^{a}$.

\begin{tabular}{|c|c|c|}
\hline$\alpha$-Amylase & $\mathbf{I}$ & $\mathbf{I}$ \\
\hline AAA85446_Paenibacillus_polymyxa & G & $\mathbf{R}$ \\
\hline CAA49465_Thermoactinomyces_vulgaris & G & A \\
\hline BAD06003_Aspergillus_awamori & $\mathbf{Y}$ & D \\
\hline BAD06002_Aspergillus_awamori & $\mathbf{Y}$ & $\mathbf{W}$ \\
\hline AAF14264_Aspergillus_flavus & $\mathbf{Y}$ & $\mathbf{W}$ \\
\hline BAD01051_Aspergillus_kawachii & $\mathbf{Y}$ & $\mathbf{W}$ \\
\hline BAA22993_Aspergillus_kawachii & $\mathbf{Y}$ & D \\
\hline EAA64850_Aspergillus_nidulans & $\mathbf{Y}$ & $\mathbf{Y}$ \\
\hline AAF17100_Aspergillus_nidulans & $\mathbf{S}$ & $\mathrm{T}$ \\
\hline P56271_Aspergillus_niger & $\mathbf{Y}$ & D \\
\hline CAK44871_Aspergillus_niger & $\mathbf{Y}$ & $\mathbf{W}$ \\
\hline CAK40249_Aspergillus_niger & $\mathbf{V}$ & $\mathbf{Y}$ \\
\hline CAK41088_Aspergillus_niger & $\mathbf{S}$ & $\mathbf{Y}$ \\
\hline CAA31218_Aspergillus_oryzae & $\mathbf{Y}$ & $\mathbf{W}$ \\
\hline BAA01255_Aspergillus_shirousami & $\mathbf{Y}$ & $\mathbf{W}$ \\
\hline AEB80431_Aspergillus_tubingensis & $\mathbf{Y}$ & $\mathbf{D}$ \\
\hline BAA12010_Cryptococcus_sp_S_2 & $\mathbf{Y}$ & Q \\
\hline ABG48762_Fusicoccum_sp_BCC4124 & $\mathbf{Y}$ & $\mathbf{W}$ \\
\hline AAO12212_Lipomyces_kononenkoae & $\mathbf{D}$ & $\mathbf{V}$ \\
\hline AAC49622_Lipomyces_spencermartinsiae & $\mathbf{Y}$ & $\mathbf{W}$ \\
\hline AAN75021_Lipomyces_starkeyi & $\mathbf{Y}$ & $\mathbf{W}$ \\
\hline AFD54462_Malbranchea_cinnamomea & $\mathbf{T}$ & $\mathrm{D}$ \\
\hline
\end{tabular}


Table 2. Cont.

\begin{tabular}{ccc}
\hline a-Amylase & $\mathbf{I}$ & $\mathbf{I}$ \\
\hline ABF72529_Ophiostoma_floccosum & $\mathbf{S}$ & $\mathbf{S}$ \\
EPS26265_Penicillium_oxalicum & $\mathbf{S}$ & $\mathbf{N}$ \\
ABO42285_Phanerochaete_chrysosporium & $\mathbf{S}$ & $\mathbf{E}$ \\
BAW15173_Pholiota_microspora & $\mathbf{K}$ & $\mathbf{Q}$ \\
BAF98616_Pichia_burtonii & $\mathbf{T}$ & $\mathbf{S}$ \\
AGJ52081_Rhizomucor_pusillus & $\mathbf{T}$ & $\mathbf{M}$ \\
ADL28123_Rhizopus_oryzae & $\mathbf{T}$ & $\mathbf{M}$ \\
ADD80242_Saccharomycopsis_fibuligera & $\mathbf{S}$ & $\mathbf{S}$ \\
ABS76467_Saitozyma_flava & $\mathbf{Y}$ & $\mathbf{Q}$ \\
CAB11471_Schizosaccharomyces_pombe & $\mathbf{S}$ & $\mathbf{H}$ \\
CAB40006_Schizosaccharomyces_pombe & $\mathbf{S}$ & $\mathbf{Q}$ \\
CAA34162_Schwanniomyces_occidentalis & $\mathbf{Y}$ & $\mathbf{S}$ \\
CAA51912_Schwanniomyces_occidentalis & $\mathbf{Y}$ & $\mathbf{D}$ \\
ACN82436_Sclerotinia_sclerotiorum & $\mathbf{Y}$ & $\mathbf{Y}$ \\
CAA03110_Thermomyces_lanuginosus & $\mathbf{S}$ & $\mathbf{K}$ \\
BAG6958_Trichoderma_viride & $\mathbf{N}$ & $\mathbf{K}$ \\
CAJ21046_Valsaria_rubricosa & $\mathbf{N}$ & $\mathbf{V}$
\end{tabular}

$\bar{a}$ The potential SBSs in $\alpha$-amylases from the subfamily GH13_1 have been analysed according to SBS-I observed in the three-dimensional structure of the counterpart $\alpha$-amylase from Aspergillus niger ([49]; PDB code: 2GVY): Y402 (Y382) and W405 (W385) - the numbering in parentheses applies if the N-terminal signal peptide is removed), which is highlighted by red-colour inversion. The individual $\alpha$-amylases are presented by their GenBank accession Nos. and binomial name of the producing organism. The aromatic residues corresponding with the two forming the real SBS-I are highlighted by black inversion.

With regard to the subfamily GH13_5, residues Phe257 and Y358 forming the SBS of the $\alpha$-amylase from B. licheniformis (paralicheniformis) [51] were best conserved, although the former residue was observed being substituted by leucine, while the latter one was replaced by valine, arginine, leucine and isoleucine (Table 3). The two residues-Trp347 and Tyr363-from the SBS-II and SBS-III, respectively, of B. halmapalus $\alpha$-amylase [50] were also found as almost totally conserved; the position of Trp347 was in some cases occupied by asparagine, serine and lysine, whereas valine, arginine, leucine and isoleucine were present in that of Tyr363. The residues defining the SBS-I of this $\alpha$-amylase, i.e., Trp439 and Trp469, belong to less conserved residues because in the position of Trp439, there is often an arginine or threonine and serine, and the Trp469 is substituted rather frequently by asparagine or glutamic acid. Concerning the SBSs from the H. orenii $\alpha$-amylase AmyB [52], the residues Trp260 and Trp287 (SBS-II) and eventually also the Trp306 (SBS-III) rank among the best conserved positions, while the remaining ones were either less or even not conserved at all (Table 3).

Table 3. Residues corresponding with SBSs of $\alpha$-amylases from B. halmapalus, B. licheniformis and H. orenii ${ }^{a}$.

\begin{tabular}{|c|c|c|c|c|c|c|c|c|c|c|c|c|}
\hline$\alpha$-Amylase & I & I & II & III & I & I & I & I & II & II & III & III \\
\hline AWX66236_Alicyclobacillus_sp_18711 & $\mathbf{T}$ & $\mathbf{N}$ & $\mathbf{W}$ & $\mathbf{Y}$ & $\mathbf{F}$ & $\mathbf{Y}$ & D & $\mathbf{I}$ & $\mathbf{W}$ & $\mathbf{W}$ & $\mathbf{W}$ & G \\
\hline AAQ01675_Alkalimonas_amylolytica & $\mathbf{S}$ & $\mathbf{Y}$ & $\mathbf{N}$ & $\mathbf{V}$ & $\mathbf{F}$ & $\mathbf{V}$ & I & $\mathbf{F}$ & W & - & $\mathbf{N}$ & - \\
\hline CAL14744_Anoxybacillus_flavithermus & $\mathbf{W}$ & $\mathbf{W}$ & $\mathbf{W}$ & $\mathbf{Y}$ & $\mathbf{F}$ & $\mathbf{Y}$ & $\mathbf{P}$ & I & $\mathbf{W}$ & $\mathbf{W}$ & $\mathbf{W}$ & G \\
\hline AEW07376_Bacillus_acidicola & $\mathbf{W}$ & $\mathbf{W}$ & $\mathbf{W}$ & $\mathbf{Y}$ & $\mathbf{F}$ & $\mathbf{Y}$ & $\mathbf{P}$ & I & $\mathbf{W}$ & $\mathbf{W}$ & $\mathbf{W}$ & G \\
\hline AAA22191_Bacillus_amyloliquefaciens & $\mathbf{R}$ & $\mathbf{W}$ & $\mathbf{W}$ & $\mathbf{Y}$ & $\mathbf{F}$ & $\mathbf{Y}$ & $\mathbf{T}$ & $\mathbf{T}$ & W & $\mathbf{W}$ & $\mathbf{W}$ & $\mathrm{G}$ \\
\hline ABY86223_Bacillus_cereus & $\mathbf{W}$ & $\mathbf{W}$ & $\mathbf{W}$ & $\mathbf{Y}$ & $\mathbf{F}$ & $\mathbf{Y}$ & $\mathbf{P}$ & $\mathbf{T}$ & W & $\mathbf{W}$ & $\mathbf{W}$ & $\mathrm{G}$ \\
\hline CAD26699_Bacillus_halmapalus & $\mathbf{W}$ & $\mathbf{W}$ & $\mathbf{W}$ & $\mathbf{Y}$ & $\mathbf{F}$ & $\mathbf{Y}$ & $\mathbf{E}$ & I & W & $\mathbf{W}$ & $\mathbf{W}$ & $\mathrm{G}$ \\
\hline AAA22226_Bacillus_licheniformis & $\mathbf{R}$ & $\mathbf{W}$ & $\mathbf{W}$ & $\mathbf{Y}$ & $\mathbf{F}$ & $\mathbf{Y}$ & $\mathbf{T}$ & $\mathbf{T}$ & $\mathbf{W}$ & $\mathbf{W}$ & $\mathbf{W}$ & G \\
\hline AEM05860_Bacillus_licheniformis & $\mathbf{R}$ & $\mathbf{W}$ & $\mathbf{W}$ & $\mathbf{Y}$ & $\mathbf{F}$ & $\mathbf{Y}$ & $\mathbf{T}$ & $\mathbf{T}$ & $\mathbf{W}$ & $\mathbf{W}$ & $\mathbf{W}$ & G \\
\hline AAK00598_Bacillus_megaterium & $\mathbf{W}$ & $\mathbf{W}$ & $\mathbf{W}$ & $\mathbf{Y}$ & $\mathbf{F}$ & $\mathbf{Y}$ & $\mathbf{P}$ & $\mathrm{T}$ & $\mathbf{W}$ & $\mathbf{W}$ & $\mathbf{W}$ & G \\
\hline AGN35141_Bacillus_paralicheniformis & $\mathbf{R}$ & $\mathbf{W}$ & $\mathbf{W}$ & $\mathbf{Y}$ & $\mathbf{F}$ & $\mathbf{Y}$ & $\mathbf{T}$ & $\mathbf{T}$ & $\mathbf{W}$ & $\mathbf{W}$ & $\mathbf{W}$ & $\mathrm{G}$ \\
\hline AAR68734_Bacillus_sp & $\mathbf{W}$ & $\mathbf{W}$ & $\mathbf{W}$ & $\mathbf{Y}$ & $\mathbf{F}$ & $\mathbf{Y}$ & $\mathbf{S}$ & I & $\mathbf{W}$ & $\mathbf{W}$ & $\mathbf{W}$ & G \\
\hline AAA22231_Bacillus_sp_707 & $\mathbf{W}$ & $\mathbf{W}$ & $\mathbf{W}$ & $\mathbf{Y}$ & $\mathbf{F}$ & $\mathbf{Y}$ & $\mathbf{E}$ & I & $\mathbf{W}$ & $\mathbf{W}$ & $\mathbf{W}$ & G \\
\hline BAF03567_Bacillus_sp_JAMB_204 & $\mathbf{R}$ & $\mathbf{W}$ & $\mathbf{W}$ & $\mathbf{Y}$ & $\mathbf{F}$ & $\mathbf{Y}$ & $\mathbf{S}$ & $\mathbf{T}$ & $\mathbf{Y}$ & $\mathbf{Y}$ & $\mathbf{W}$ & G \\
\hline CAC39917_Bacillus_sp_KSM_K38 & $\mathbf{W}$ & $\mathbf{W}$ & $\mathbf{W}$ & $\mathbf{Y}$ & $\mathbf{F}$ & $\mathbf{Y}$ & D & I & $\mathbf{W}$ & $\mathbf{W}$ & $\mathbf{W}$ & G \\
\hline
\end{tabular}


Table 3. Cont.

\begin{tabular}{|c|c|c|c|c|c|c|c|c|c|c|c|c|}
\hline$\alpha$-Amylase & I & I & II & III & I & I & I & $\mathbf{I}$ & II & II & III & III \\
\hline AAB18785_Bacillus_sp_MK_716 & $\mathbf{W}$ & W & $\mathbf{W}$ & $\mathbf{Y}$ & $\mathbf{F}$ & $\mathbf{Y}$ & $\mathbf{P}$ & I & $\mathbf{W}$ & $\mathbf{W}$ & $\mathbf{W}$ & G \\
\hline AAA63900_Bacillus_sp_TS_23 & $\mathbf{W}$ & $\mathbf{W}$ & $\mathbf{W}$ & $\mathbf{Y}$ & $\mathbf{F}$ & $\mathbf{Y}$ & $\mathbf{P}$ & I & $\mathbf{W}$ & $\mathbf{W}$ & $\mathbf{W}$ & G \\
\hline ABW87262_Bacillus_sp_YX_YX1 & $\mathbf{R}$ & $\mathbf{W}$ & $\mathbf{W}$ & $\mathbf{Y}$ & $\mathbf{F}$ & $\mathbf{Y}$ & $\mathbf{T}$ & $\mathbf{T}$ & $\mathbf{W}$ & $\mathbf{W}$ & $\mathbf{W}$ & G \\
\hline AAF00567_Cytophaga_sp & $\mathbf{R}$ & $\mathbf{Y}$ & $\mathbf{W}$ & $\mathbf{Y}$ & $\mathbf{F}$ & $\mathbf{Y}$ & $\mathbf{P}$ & $\mathbf{T}$ & $\mathbf{W}$ & $\mathbf{W}$ & $\mathbf{W}$ & G \\
\hline AAC74994_Escherichia_coli & $\mathbf{T}$ & $\mathbf{E}$ & $\mathbf{W}$ & $\mathbf{V}$ & $\mathbf{F}$ & $\mathbf{V}$ & $\mathbf{P}$ & A & $\mathbf{W}$ & $\mathbf{H}$ & $\mathbf{W}$ & G \\
\hline AFZ41193_Exiguobacterium_sp_DAU5 & $\mathbf{W}$ & $\mathbf{W}$ & $\mathbf{W}$ & $\mathbf{Y}$ & $\mathbf{F}$ & $\mathbf{Y}$ & $\mathbf{N}$ & $\mathbf{T}$ & $\mathbf{W}$ & $\mathbf{W}$ & $\mathbf{S}$ & G \\
\hline AAA22235_Geobacillus_stearothermophilus & $\mathbf{W}$ & $\mathbf{W}$ & $\mathbf{W}$ & $\mathbf{Y}$ & $\mathbf{F}$ & $\mathbf{Y}$ & $\mathbf{P}$ & $\mathbf{I}$ & $\mathbf{W}$ & $\mathbf{W}$ & $\mathbf{W}$ & G \\
\hline ABX83871_Geobacillus_thermodenitrificans & $\mathbf{W}$ & $\mathbf{R}$ & $\mathbf{W}$ & $\mathbf{R}$ & $\mathbf{F}$ & $\mathbf{R}$ & $\mathbf{P}$ & $\mathbf{I}$ & $\mathbf{W}$ & $\mathbf{W}$ & $\mathbf{F}$ & $\mathbf{K}$ \\
\hline AFC87833_Geobacillus_thermoleovorans & $\mathbf{W}$ & $\mathbf{W}$ & $\mathbf{W}$ & $\mathbf{Y}$ & $\mathbf{F}$ & $\mathbf{Y}$ & $\mathbf{P}$ & I & $\mathbf{W}$ & $\mathbf{W}$ & $\mathbf{W}$ & G \\
\hline ACL70573_Halothermothrix_orenii & $\mathbf{W}$ & $\mathbf{Y}$ & $\mathbf{S}$ & $\mathbf{V}$ & $\mathbf{F}$ & $\mathbf{V}$ & $\mathbf{Y}$ & $\mathbf{W}$ & $\mathbf{W}$ & $\mathbf{W}$ & $\mathbf{W}$ & $\mathbf{W}$ \\
\hline CAQ30277_Nostoc_sp_PCC_7119 & $\mathbf{W}$ & $\mathbf{W}$ & $\mathbf{W}$ & $\mathbf{Y}$ & $\mathbf{F}$ & $\mathbf{Y}$ & $\mathbf{P}$ & $\mathbf{A}$ & $\mathbf{Y}$ & $\mathbf{Y}$ & D & G \\
\hline AAA27110_Salmonella_typhimurium & $\mathbf{T}$ & $\mathbf{E}$ & $\mathbf{W}$ & $\mathbf{V}$ & $\mathbf{F}$ & $\mathbf{V}$ & $\mathbf{P}$ & $\mathbf{A}$ & $\mathbf{W}$ & $\mathbf{H}$ & $\mathbf{W}$ & G \\
\hline BAA24178_Streptococcus_equinus & $\mathbf{R}$ & $\mathbf{Y}$ & $\mathbf{W}$ & $\mathbf{L}$ & $\mathbf{Y}$ & $\mathbf{L}$ & $\mathbf{E}$ & I & $\mathbf{W}$ & $\mathbf{Y}$ & $\mathbf{N}$ & G \\
\hline AAA97431_Streptococcus_equinus & $\mathbf{R}$ & $\mathbf{Y}$ & $\mathbf{W}$ & $\mathbf{L}$ & $\mathbf{Y}$ & $\mathbf{L}$ & $\mathbf{E}$ & I & $\mathbf{W}$ & $\mathbf{Y}$ & $\mathbf{N}$ & G \\
\hline AAN59233_Streptococcus_mutans & $\mathbf{R}$ & $\mathbf{W}$ & $\mathbf{W}$ & I & $\mathbf{Y}$ & $\mathbf{I}$ & $\mathbf{E}$ & I & $\mathbf{W}$ & $\mathbf{Y}$ & $\mathbf{S}$ & G \\
\hline CCD30600_uncultured_bacterium & $\mathbf{R}$ & $\mathbf{Y}$ & $\mathbf{K}$ & $\mathbf{I}$ & $\mathbf{F}$ & $\mathbf{I}$ & $\mathbf{Y}$ & $\mathbf{Y}$ & $\mathbf{W}$ & $\mathbf{W}$ & $\mathbf{Y}$ & $\mathbf{R}$ \\
\hline ALP73597_Vibrio_alginolyticus & $\mathbf{W}$ & $\mathbf{W}$ & $\mathbf{W}$ & $\mathbf{Y}$ & $\mathbf{F}$ & $\mathbf{Y}$ & $\mathbf{W}$ & A & $\mathbf{W}$ & $\mathbf{W}$ & $\mathbf{W}$ & G \\
\hline ABK62854_Histoplasma_capsulatum & $\mathbf{R}$ & $\mathbf{Y}$ & $\mathbf{F}$ & $\mathbf{Y}$ & $\mathbf{L}$ & $\mathbf{Y}$ & $\mathbf{D}$ & V & $\mathbf{W}$ & $\mathbf{F}$ & $\mathbf{W}$ & G \\
\hline ABS11196_Paracoccidioides_brasiliensis & $\mathbf{R}$ & $\mathbf{Y}$ & $\mathbf{F}$ & $\mathbf{Y}$ & $\mathbf{F}$ & $\mathbf{Y}$ & $\mathbf{E}$ & $\mathbf{L}$ & $\mathbf{W}$ & $\mathbf{Y}$ & $\mathbf{W}$ & G \\
\hline BAW15172_Pholiota_microspora & $\mathbf{R}$ & W & $\mathbf{N}$ & $\mathbf{Y}$ & $\mathbf{F}$ & $\mathbf{Y}$ & $\mathbf{D}$ & $\mathbf{N}$ & $\mathbf{W}$ & $\mathbf{W}$ & $\mathbf{W}$ & G \\
\hline
\end{tabular}

${ }^{a}$ The potential SBSs in $\alpha$-amylases from the subfamily GH13_5 have been analysed according to SBSs observed in the three-dimensional structures of the counterpart $\alpha$-amylases from: (i) Bacillus halmapalus ([50]; PDB code: 2GJP)—SBS-I: W439 and W469; SBS-II: W347; and SBS-III: Y363; (ii) Bacillus licheniformis ([51]; PDB code: 6TOZ)-SBS-I: F257 and Y368; and (iii) Halothermothrix orenii ([52]; PDB code: 3BC9)—SBS-I: Y484 (Y460) and W512 (W488); SBS-II: W284 (W260) and W311 (W287); and SBS-III: W330 (W306) and W334 (W310) -the numbering in parentheses applies if the N-terminal signal peptide is removed; which all are highlighted by green-colour inversion. The individual $\alpha$-amylases are presented by their GenBank accession Nos. and binomial name of the producing organism. The aromatic residues corresponding with the those forming the real SBSs are highlighted by black inversion.

The SBSs identified in the human salivary $\alpha$-amylase [54] were all, in fact, well conserved; the positions of Trp284 (SBS-I), Trp388 (SBS-II) and Trp203 (SBS-III) being found conserved invariantly (Table 4). The other three residues were in a few cases substituted by asparagine, threonine, leucine and cysteine-Trp134 (SBS-IV), threonine and asparagineTyr276 (SBS-I) and arginine-Trp316 (SBS-II).

Based on the above analysis, it is possible to assume that the SBSs experimentally identified in tertiary structures of individual $\alpha$-amylases may really exist in their homologues (Tables 2-4; cf. Figure S1). Simultaneously, it is important to take into account the fact that the SBSs, even within a particular GH13 subfamily, may be localized in different parts of $\alpha$-amylase structure-as seen, e.g., for the three bacterial $\alpha$-amylases from the subfamily GH13_5 (Table 3). In order to verify the in silico data presented here that concern the conserving the aromatic positions corresponding to real SBSs, it is necessary to confirm the involvement of homologous residues experimentally.

With regard to SBSs, a remark on SBDs, i.e., distinct domains responsible for starch or-in a wider sense $-\alpha$-glucan binding and classified as various CBM families [44], could be of interest. Some, i.e., not all, fungal and bacterial (from actinomycetes) $\alpha$-amylases from subfamilies GH13_1 and GH13_32, respectively, contain such an SBD, mostly from the family CBM20 positioned at their C-terminus; or more rarely-mainly some $\alpha$-amylases of the yeast origin - the SBD of the family CBM21 at their N-terminus [76]. The reasons why some of fungal (yeast) and actinobacterial $\alpha$-amylases do possess a distinct SBD and why some (others) exhibit rather an isolated SBS (or even more SBSs) are still not completely understood, but those $\alpha$-amylases having the distinct SBD may represent a unique group of four-domain hydrolases from the family GH13 deserving the future attention [77-79]. Concerning the fungal $\alpha$-amylases from the subfamily GH13_5, these may also represent a special group, sequentially closely similar even to liquefying $\alpha$-amylases from bacilli $[28,80]$, but most probably involved in synthesizing the $\alpha-1,4$-oligoglucan primers for synthesis of the outer $\alpha$-1,3-glucan layer in their cell walls, which behaves as a virulence factor [81-85]. 
Table 4. Residues corresponding with the SBSs from H. sapiens $\alpha$-amylase ${ }^{a}$.

\begin{tabular}{|c|c|c|c|c|c|c|}
\hline$\alpha$-Amylase & I & $\mathbf{I}$ & II & II & III & IV \\
\hline ABL09312_Acarus_siro & $\mathbf{T}$ & $\mathbf{W}$ & $\mathbf{F}$ & $\mathbf{W}$ & W & $\mathbf{N}$ \\
\hline BAB85635_Anguilla_japonica & $\mathbf{Y}$ & $\mathbf{W}$ & $\mathbf{W}$ & $\mathbf{W}$ & $\mathbf{W}$ & $\mathbf{W}$ \\
\hline AAL37207_Crassostrea_gigas & W & W & $\mathbf{Y}$ & $\mathbf{W}$ & $\mathbf{W}$ & $\mathbf{W}$ \\
\hline AAL37183_Crassostrea_gigas & W & W & $\mathbf{F}$ & $\mathbf{W}$ & W & $\mathbf{W}$ \\
\hline AAD38942_Dermatophagoides_pteronyssinus & $\mathbf{W}$ & W & $\mathbf{F}$ & $\mathbf{W}$ & $\mathbf{W}$ & $\mathbf{N}$ \\
\hline AAD38943_Euroglyphus_maynei & W & W & $\mathbf{F}$ & $\mathbf{W}$ & W & $\mathbf{N}$ \\
\hline AAC60246_Gallus_gallus & $\mathbf{Y}$ & $\mathbf{W}$ & $\mathbf{W}$ & $\mathbf{W}$ & $\mathbf{W}$ & $\mathbf{W}$ \\
\hline ABO26610_Haliotis_discus_discus & $\mathbf{Y}$ & W & $\mathbf{F}$ & $\mathbf{W}$ & $\mathbf{W}$ & $\mathrm{T}$ \\
\hline BAM74656_Haliotis_discus_hannai & $\mathbf{Y}$ & $\mathbf{W}$ & $\mathbf{F}$ & $\mathbf{W}$ & $\mathbf{W}$ & $\mathrm{T}$ \\
\hline AAA51724_Homo_sapiens (pancreas) & $\mathbf{Y}$ & W & W & W & W & $\mathbf{W}$ \\
\hline AAH63129_Homo_sapiens (saliva) & $\mathbf{Y}$ & $\mathbf{W}$ & $\mathbf{W}$ & $\mathbf{W}$ & $\mathbf{W}$ & $\mathbf{W}$ \\
\hline AAA37221_Mus_musculus & $\mathbf{Y}$ & W & W & $\mathbf{W}$ & W & $\mathbf{F}$ \\
\hline AAA37230_Mus_musculus & $\mathbf{Y}$ & W & W & $\mathbf{W}$ & W & $\mathbf{W}$ \\
\hline H2N0D4_Oryzias_latipes & $\mathbf{Y}$ & W & $\mathbf{W}$ & $\mathbf{W}$ & W & $\mathbf{L}$ \\
\hline CAA68065_Pecten_maximus & $\mathbf{N}$ & W & $\mathbf{F}$ & $\mathbf{W}$ & W & $\mathbf{W}$ \\
\hline CAA54524_Penaeus_vannamei & $\mathbf{Y}$ & W & $\mathbf{R}$ & $\mathbf{W}$ & $\mathbf{W}$ & $\mathbf{F}$ \\
\hline CAB65552_Penaeus_vannamei & $\mathbf{Y}$ & W & $\mathbf{R}$ & W & W & $\mathbf{F}$ \\
\hline AAF65827_Pseudopleuronectes_americanus & $\mathbf{Y}$ & W & W & W & W & $\mathrm{C}$ \\
\hline AAA40725_Rattus_norvegicus & $\mathbf{Y}$ & W & W & W & W & W \\
\hline AAH88228_Rattus_norvegicus & $\mathbf{Y}$ & W & $\mathbf{W}$ & $\mathbf{W}$ & $\mathbf{W}$ & $\mathbf{F}$ \\
\hline P83053_Struthio_camelus & $\mathbf{Y}$ & $\mathbf{W}$ & W & $\mathbf{W}$ & W & $\mathbf{W}$ \\
\hline AAF02828_Sus_scrofa & $\mathbf{Y}$ & W & $\mathbf{W}$ & $\mathbf{W}$ & W & $\mathbf{W}$ \\
\hline CAC87125_Tetraodon_nigroviridis & $\mathbf{Y}$ & W & $\mathbf{W}$ & $\mathbf{W}$ & $\mathbf{W}$ & $\mathrm{L}$ \\
\hline
\end{tabular}

${ }^{a}$ The potential SBSs in $\alpha$-amylases from the subfamily GH13_24 have been analysed according to SBSs observed in the three-dimensional structures of the counterpart human salivary $\alpha$-amylase ([54]; PDB code: 3BLP)—SBS-I: Y291 (Y276) and W299 (W284); SBS-II: W331 (W316) and W403 (W388); SBS-III: W218 (W203); and SBS-IV: W149 (W134) -the numbering in parentheses applies if the N-terminal signal peptide is removed); which is highlighted by the walnut-colour inversion. The individual $\alpha$-amylases are presented by their GenBank accession Nos. and the binomial name of the producing organism. The aromatic residues corresponding with the those forming the real SBSs are highlighted by black inversion.

\subsection{Evolutionary Relatedness of $\alpha$-Amylases from Fungi and Other Taxa}

The phylogenetic relationships between fungal and chloride-dependent $\alpha$-amylases are shown in their evolutionary trees (Figure 2). Two trees have been prepared: (i) one (Figure 2A) based on the alignment (718 positions) spanning the segment of sequences from beginning of the strand $\beta 1$ (CSR-VIII) to the end of the strand $\beta 8$ (CSR-VII) of the catalytic TIM-barrel domain including the entire domain B (cf. Figure S1); and (ii) the other one (Figure 2B) based on the alignment of eight extracted CSRs, i.e., only 55 positions (cf. Figure 1) that may represent the so-called sequence fingerprints of the $\alpha$-amylases family GH13 [1,18,21-30]. In order to emphasize just the clustering of individual subfamilies and/or their groups as well as for a higher clarity, the details of all particular 268 sequences (Table S1) were removed in the trees. However, the same evolutionary trees with all the details of individual sources, i.e., mainly the origin and database accession number, are shown in Figure S2.

It is obvious that despite the identical catalytic machinery and substantial similarities within all CSRs (Figure 1), each GH13 subfamily keeps its uniqueness and independency. Nevertheless, it is also clear that $\alpha$-amylases from the subfamily GH13_42 exhibit a closer evolutionary relatedness with their counterparts from subfamilies GH13_1 and GH13_5 (Figure 2). The subfamily GH13_5 might be of a special importance since it was originally established as a subfamily for liquefying bacterial $\alpha$-amylases originating mainly from bacilli [1,20], but later some fungal counterparts have been revealed as worth to be included [28]. Of interest is also a hypothetical GH13_5 $\alpha$-amylase from psychrophilic yeast Glaciozyma antarctica exhibiting all sequence-structural features typical for GH13_5 subfamily members, but it still awaits its biochemical characterization [86]. This subfamily has recently expanded its taxonomic coverage even towards Archaea [6]. This is rather similar with subfamilies GH13_6 and GH13_7 that were originally defined for $\alpha$-amylases from 
plants and hyperthermophilic archaeons, respectively [20,25,87], but currently, both subfamilies contain experimentally confirmed bacterial $\alpha$-amylases $[1,6,7,21,88,89]$. Moreover, recent studies focused on the NF-Daqu, i.e., a fermentation starter for a Chinese liquor, have shown $[90,91]$ that a total of 15 GH13 $\alpha$-amylases- 10 from the subfamily GH13_1 and 5 from the subfamily GH13_5-may be involved in the processing, both members of GH13_1 and GH13_5 demonstrating a high synergistic effect on starch degradation [91]. The evolutionary relationships among various fungal $\alpha$-amylases based on analysis of 85 genomes and focused on taxonomy of fungi have been described in an insightful phylogenetic study in 2012 [92]. Unfortunately, it was performed before the additional GH13 subfamilies with fungal $\alpha$-amylases (especially the GH13_32) were established; that analysis would therefore deserve to be updated.
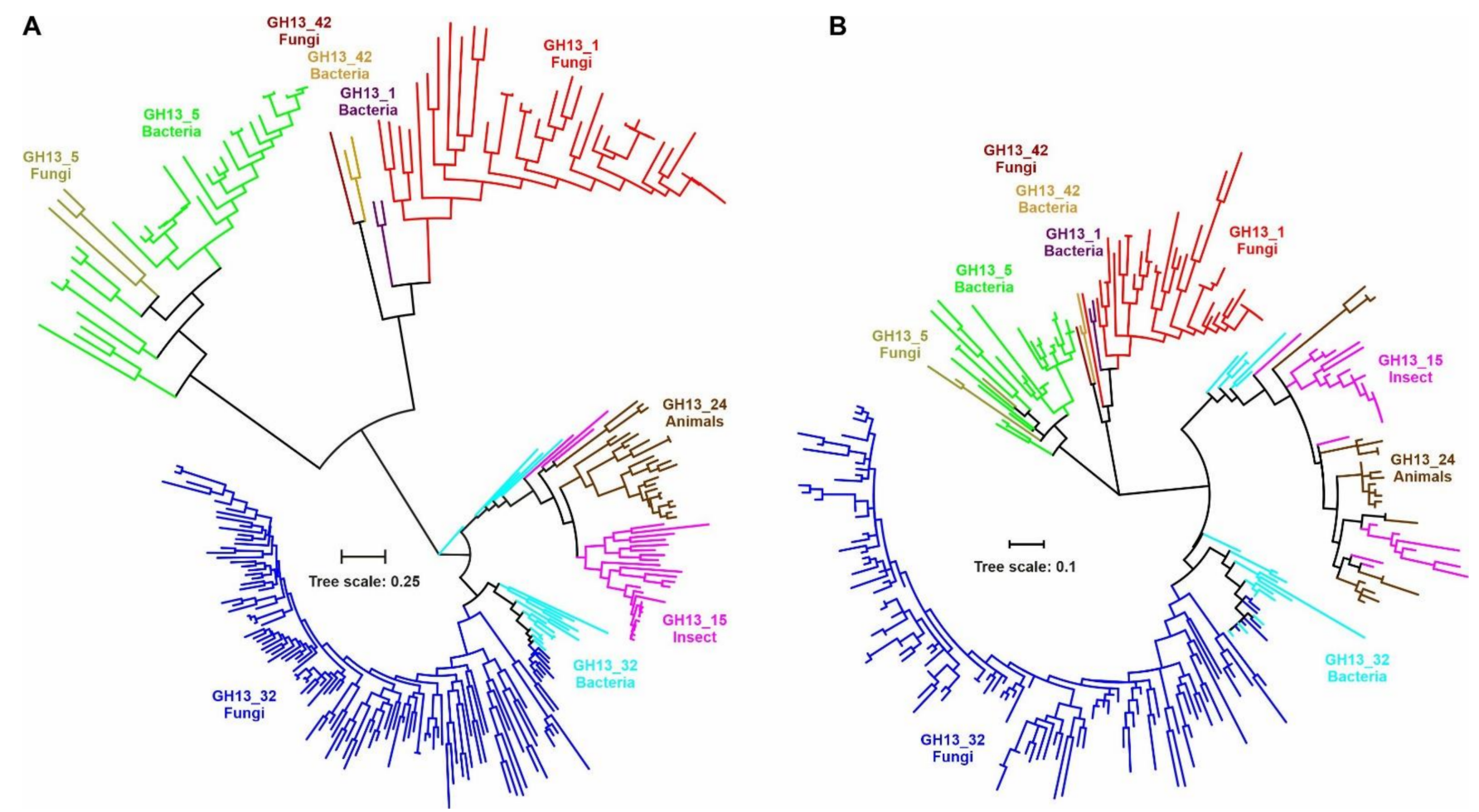

Figure 2. Evolutionary trees of all $268 \alpha$-amylases from six studied GH13 subfamilies. The trees are based on the alignment spanning the sequence segment between the strands $\beta 1$ and $\beta 8$ of catalytic TIM-barrel (A) and covering just CSRs (B). For the sake of simplicity, only the branches are shown. The same trees with all the leaves described are presented in supplementary Figure S2. Details concerning all $\alpha$-amylases compared in the tree as well as their colour codes are given in Table S1.

Further, fungal $\alpha$-amylases along with most bacterial $\alpha$-amylases from actinomycetesincluding the one from Bacillus sp. 195 ([93]; BAA22082.1)—from the subfamily GH13_32 form their own cluster, too. The additional GH13_32 $\alpha$-amylases from remaining bacteriaincluding, on the other hand, also two $\alpha$-amylases from actinobacteria Thermobifida fusca ([62]; GenBank: ABF13430.1) and Thermomonospora curvata ([63]; CAA41881.1)—are positioned adjacently to their animal counterparts from subfamilies GH13_15 and GH13_24 to form a larger cluster with them (Figure S2). The two actinobacterial enzymes stand even separately in the evolutionary tree based on the alignment of the sequence segment from beginning of the strand $\beta 1$ to the end of the strand $\beta 8$ (Figure $2 \mathrm{~A}$ ). This finding just confirms the original postulate [25] that one may observe some subtle differences in evolutionary trees calculated on alignments of complete sequences and isolated CSRs. The GH13_32 bacterial $\alpha$-amylases—outside actinobacteria—clustering with the chlorideactivated GH13_15 and GH13_24 $\alpha$-amylases from animals—come from Halomonas meridi- 
ana ([60]; CAB92963.1), Pseudoalteromonas haloplanktis ([31]; CAA41481.1), Pseudomonas sp. KFCC10818 ([61]; AAA86835.1) and Aeromonas hydrophila ([94]; AAA21016.1).

It is of note that this evolutionary relatedness has been described previously [1,26,29], even before the $\alpha$-amylase from P. haloplanktis [31-35] was assigned to subfamily GH13_32 [6]. What is, however, more important is that all these six bacterial $\alpha$-amylases closely related to animal counterparts should be able to bind the chloride anion, i.e., to be chloride-activated, since they possess all the three residues identified as crucial $\mathrm{Cl}^{-}$-binding residues; with the eventual exception of the A. hydrophila $\alpha$-amylase having in the position of the third residue - being Arg/Lys—a glutamine (cf. Figure S1; CSR-VII).

Concerning the subfamily GH13_15, the $\alpha$-amylases from the starfish Asterias rubens ([95]; AAO13755.1), cockroach Blattella germanica ([96]; AAY23288.1) and one of the two from mosquito Aedes aegypti ([97]; AAB60935.1) may be of a special interest, since-in the evolutionary tree based on the alignment of the larger sequence segment (from strand $\beta 1$ to strand $\beta 8$; Figure 2A; Figure S2A) — they occupy positions at the border of the cluster, common for both GH13_15 and GH13_24, and outside the rest of the subfamily GH13_15 members. Note that in the CSR-based tree (Figure 2B and Figure S2B), sequences from both animal GH13 subfamilies 15 and 24 are rather scattered or mixed to each other within their cluster, indicating thus their mutual very close evolutionary relationships.

\subsection{Conclusions}

The present bioinformatics study has been devoted to - by in silico approaches—-the sequences of $268 \alpha$-amylases from six subfamilies GH13_1, GH13_5, GH13_15, GH13_24, GH13_32 and GH13_42 of the main $\alpha$-amylase family GH13. The analyses were focused on fungal $\alpha$-amylases classified in four of the six studied subfamilies $(1,5,32$ and 42$)$ with a special emphasis on the subfamily GH13_32 containing also bacterial $\alpha$-amylases closely related to animal counterparts from subfamilies GH13_15 and GH13_24. Since most of animal $\alpha$-amylases are chloride-activated, including also some bacterial homologues from the subfamily GH13_32, the attention was paid to investigate whether or not fungal $\alpha$ amylases from the subfamily GH13_32 could bind the chloride anion, too. This is, however, rather impossible since they do not possess the complete triad of required binding residues. The additional goal of the study was to make a sequence comparison concerning the eventual presence of secondary surface-binding sites observed experimentally in several tertiary structures of a few $\alpha$-amylases from subfamilies GH13_1, GH13_5 and GH13_24 determined as complexes with $\alpha$-glucans. It was seen that the conservation of these sites cannot be generalized even within a particular GH13 subfamily. With regard to evolutionary relationships, the members of subfamilies GH13_15, GH13_24 and GH13_32 clustered together, whereas members of the subfamily GH13_5 were seemingly more related to those from both GH13_1 and GH13_42 that exhibit very close relatedness to each other. In summary, the present study together with the previous one [30] may add to the overall understanding of evolutionary relationships within the $\alpha$-amylase family GH13 and the knowledge of properties of $\alpha$-amylases originating from various taxonomic sources. In a wider perspective, these results may become a base for future experiments aimed at protein engineering and design of $\alpha$-amylases.

\section{Materials and Methods}

\subsection{Sequence Collection}

The study has dealt with fungal and chloride-dependent GH13 $\alpha$-amylases classified in the subfamilies GH13_1, GH13_5, GH13_32 and GH13_42 (subfamilies containing the fungal $\alpha$-amylases) and GH13_15, GH13_24 and GH13_32 (chloride-dependent, respectively, insect, animal and animal-like bacterial $\alpha$-amylases). Sequences were first taken from the CAZy database [6] focusing on experimentally characterized members of the above-mentioned subfamilies. Since the subfamily GH13_42 has contained only one fungal (eukaryotic) member, the putative fungal $\alpha$-amylase from Pecoramyces ruminatium was added. With regard to the subfamily GH13_32, it has also not covered any biochemically 
characterized $\alpha$-amylases originating from fungi (Eucarya); putative $\alpha$-amylase of fungal origin were therefore included. In addition, further fungal $\alpha$-amylases were obtained by the protein BLAST search ([98]; https:/ /blast.ncbi.nlm.nih.gov/Blast.cgi (accessed on 19 March 2019)), using the complete amino acid sequence of fungal $\alpha$-amylase from Pholiota microspora (UniProt Accession No.: A0A1E1ERR9; [99]), which has been classified in CAZy in the subfamily GH13_32 [6]. The reason for using this fungus as the sequence query for performing the BLAST search was that $P$. microspora, although being a mushroom, possesses in its genome the genes coding for $\alpha$-amylases from all the three GH13 subfamilies 1, 5 and $32[6]$.

All selected sequences had to possess the $\alpha$-amylase family GH13 characteristic features, such as complete catalytic triad and convincingly typical CSRs. Many eventual sequences exhibited high sequence similarity and even identity (e.g., insect $\alpha$-amylases from various drosophilas from the subfamily GH13_15); the number of resulting sequences was therefore reduced accordingly (i.e., at the level $>90 \%$ of sequence identity, only one sequence from that particular group was taken into comparison). Overall, 268 sequences were collected (Table S1) as follows: (i) subfamily GH13_1-39 sequences; (ii) subfamily GH13_5-35 sequences; (iii) subfamily GH13_15-28 sequences; (iv) GH13_24-23 sequences; (v) GH13_32-140 sequences; and (vi) GH13_42-3 sequences.

\subsection{Sequence Analysis}

All 268 studied sequences (Table S1) were obtained from GenBank ([100]; https:// www.ncbi.nlm.nih.gov/genbank/) or UniProt ([101]; https://www.uniprot.org/) databases. Their alignment was done using the program Clustal-Omega ([102]; https:/ /www.ebi.ac. $\mathrm{uk} /$ Tools/msa/clustalo/) available on the European Bioinformatics Institute's server. The alignment, which included the necessary but gentle manual tuning with regard to correct alignment of all CSRs $[1,18]$, was manually cut at the $\mathrm{N}$-terminus to start each sequence by the stretch representing the beginning of the strand $\beta 1$ (CSR-VIII) of the catalytic TIMbarrel domain. With regard to the C-terminus, one version of the alignment was cut just after the end of the strand $\beta 8$ (CSR-VII), whereas the other one was kept longer bearing also a segment of the domain $\mathrm{C}$ succeeding the catalytic TIM-barrel. The former alignment was used for calculating the evolutionary tree and the latter served for identifying the residues involved in secondary SBSs.

Sequence logos of eight CSRs were created using the WebLogo3 online server ([103]; http:/ / weblogo.threeplusone.com/). Seven sequence logos were calculated-the first one for all studied sequences; whereas the additional logos were prepared for the six individual GH13 subfamilies GH13_1, 5, 15, 24, 32 and 42.

\subsection{Comparison of Chloride- and Surface-Binding Sites}

The experimentally determined three-dimensional structures of chloride-activated $\alpha$-amylases were retrieved from Protein Data Bank (PDB; [104]; https:/ / www.rcsb.org/): (i) subfamily GH13_15-Tenebrio molitor ([40]; PDB code: 1JAE); (ii) subfamily GH13_24:Sus scrofa (pancreas; [41]; PDB: 1WO2), Homo sapiens (saliva; [39]; PDB: 1SMD); and (iii) subfamily GH13_32-Pseudoalteromonas haloplanktis ([35]; PDB: 1JD7). The eventual presence of a chloride-binding site in individual $\alpha$-amylases from the entire studied set of 268 sequences was evaluated with respect to conserving the residues involved in binding the chloride anion in the above structures by their comparison in the sequence alignment.

The structures of $\alpha$-amylases solved as complexes with identified additional SBSs were also obtained from PDB [104]: (i) subfamily GH13_1—Aspergillus niger ([49]; PDB: 2GUY); (ii) subfamily GH13_5—Bacillus halmapalus ([50]; PDB: 2GJP); Bacillus paralicheniformis ([51]; PDB: 6TOZ) and Halothermothrix orenii ([52]; PDB: 3BC9); and (iii) subfamily GH13_24Homo sapiens (saliva; [54]; PDB: 3BLP). The possible existence of a corresponding SBS in individual $\alpha$-amylases from the three subfamilies GH13_1, 5 and 24 was deduced from the inspection of the above tertiary structures with experimentally observed SBSs and by the comparison of relevant residues within the sequence alignment. 


\title{
3.4. Evolutionary Relationships
}

Two evolutionary trees were prepared: (i) one based on the alignment of the segment from the beginning of the strand $\beta 1$ (CSR-VIII) to the end of the strand $\beta 8$ (CSR-VII) of the catalytic TIM-barrel domain, including the domain B of all 268 studied sequences; and (ii) the other one based on the alignment of eight selected CSRs for the same sample of all 268 sequences. Both evolutionary trees were calculated as maximum-likelihood trees [105] using the bootstrapping procedure with 500 bootstrap trials [106] implemented in the MEGA software ([107]; https:/ / www.megasoftware.net/) applying default program parameters. The trees were displayed with the program iTOL ([108]; http://itol.embl.de/).

Supplementary Materials: Figure S1: Sequence alignment of all 268 collected sequences representing $\alpha$-amylases from subfamilies GH13_1, GH13_5, GH13_15, GH13_24, GH13_32 and GH13_42. Figure S2: Evolutionary trees of studied $\alpha$-amylases based on the alignment of (a) sequences spanning the segment between the strands $\beta 1$ and $\beta 8$ of catalytic TIM-barrel; and (b) extracted eight conserved sequence regions. Table S1: List of 268 sequences from GH13 subfamilies containing fungal and chloride-dependent $\alpha$-amylases.

Author Contributions: Z.J. collected data, analysed results, prepared figures and contributed to writing the manuscript; Š.J. designed the study, contributed to collecting data, analysed and interpreted results, prepared figures and wrote the manuscript. All authors have read and agreed to the published version of the manuscript.

Funding: This research was funded by VEGA, the Grant Agency of the Slovak Academy of Sciences, grant number 2/0146/21.

Institutional Review Board Statement: Not applicable.

Informed Consent Statement: Not applicable.

Data Availability Statement: Not applicable.

Conflicts of Interest: The authors declare no conflict of interest.

\begin{abstract}
Abbreviations
CAZy: Carbohydrate-Active enZymes; CBM: carbohydrate-binding module; CSR: conserved sequence region; GH: glycoside hydrolase; PDB: Protein Data Bank; SBD: starch-binding domain; SBS: surface-binding site.
\end{abstract}

\section{References}

1. Janecek, S.; Svensson, B.; MacGregor, E.A. $\alpha$-Amylase: An enzyme specificity found in various families of glycoside hydrolases. Cell. Mol. Life Sci. 2014, 71, 1149-1170. [CrossRef]

2. Pujadas, G.; Palau, J. Evolution of $\alpha$-amylases: Architectural features and key residues in the stabilization of the $(\beta / \alpha)(8)$ scaffold. Mol. Biol. Evol. 2001, 18, 38-54. [CrossRef]

3. Linden, A.; Wilmanns, M. Adaptation of class-13 $\alpha$-amylases to diverse living conditions. Chembiochem 2004, 5, 231-239. [CrossRef]

4. Mehta, D.; Satyanarayana, T. Bacterial and archaeal $\alpha$-amylases: Diversity and amelioration of the desirable characteristics for industrial applications. Front. Microbiol. 2016, 7, 1129. [CrossRef]

5. Bozic, N.; Loncar, N.; Slavic, M.S.; Vujcic, Z. Raw starch degrading $\alpha$-amylases: An unsolved riddle. Amylase 2017, 1, 12-25. [CrossRef]

6. Lombard, V.; Golaconda Ramulu, H.; Drula, E.; Coutinho, P.M.; Henrissat, B. The carbohydrate-active enzymes database (CAZy) in 2013. Nucleic Acids Res. 2014, 42, D490-D495. [CrossRef]

7. Janecek, S.; Gabrisko, M. Remarkable evolutionary relatedness among the enzymes and proteins from the $\alpha$-amylase family. Cell. Mol. Life Sci. 2016, 73, 2707-2725. [CrossRef]

8. Blesak, K.; Janecek, S. Sequence fingerprints of enzyme specificities from the glycoside hydrolase family GH57. Extremophiles 2012, 16, 497-506. [CrossRef]

9. Janecek, S.; Kuchtova, A. In silico identification of catalytic residues and domain fold of the family GH119 sharing the catalytic machinery with the $\alpha$-amylase family GH57. FEBS Lett. 2012, 586, 3360-3366. [CrossRef] [PubMed]

10. Kerenyiova, L.; Janecek, S. A detailed in silico analysis of the amylolytic family GH126 and its possible relatedness to family GH76. Carbohydr. Res. 2020, 494, 108082. [CrossRef] 
11. Jespersen, H.M.; MacGregor, E.A.; Henrissat, B.; Sierks, M.R.; Svensson, B. Starch- and glycogen-debranching and branching enzymes: Prediction of structural features of the catalytic $(\beta / \alpha)_{8}$-barrel domain and evolutionary relationship to other amylolytic enzymes. J. Protein Chem. 1993, 12, 791-805. [CrossRef]

12. Svensson, B. Protein engineering in the $\alpha$-amylase family: Catalytic mechanism, substrate specificity, and stability. Plant Mol. Biol. 1994, 25, 141-157. [CrossRef]

13. Kuriki, T.; Imanaka, T. The concept of the $\alpha$-amylase family: Structural similarity and common catalytic mechanism. J. Biosci. Bioeng. 1999, 87, 557-565. [CrossRef]

14. MacGregor, E.A.; Janecek, S.; Svensson, B. Relationship of sequence and structure to specificity in the $\alpha$-amylase family of enzymes. Biochim. Biophys. Acta 2001, 1546, 1-20. [CrossRef]

15. van der Maarel, M.J.E.C.; van der Veen, B.; Uitdehaag, J.C.; Leemhuis, H.; Dijkhuizen, L. Properties and applications of starch-converting enzymes of the $\alpha$-amylase family. J. Biotechnol. 2002, 94, 137-155. [CrossRef]

16. Matsuura, Y.; Kusunoki, M.; Harada, W.; Kakudo, M. Structure and possible catalytic residues of Taka-amylase A. J. Biochem. 1984, 95, 697-702. [CrossRef] [PubMed]

17. Uitdehaag, J.C.; Mosi, R.; Kalk, K.H.; van der Veen, B.A.; Dijkhuizen, L.; Withers, S.G.; Dijkstra, B.W. X-ray structures along the reaction pathway of cyclodextrin glycosyltransferase elucidate catalysis in the $\alpha$-amylase family. Nat. Struct. Biol. 1999, 6, 432-436. [CrossRef]

18. Janecek, S. How many conserved sequence regions are there in the $\alpha$-amylase family? Biologia 2002, 57 (Suppl. 11), $29-41$.

19. Oslancova, A.; Janecek, S. Oligo-1,6-glucosidase and neopullulanase enzyme subfamilies from the $\alpha$-amylase family defined by the fifth conserved sequence region. Cell. Mol. Life Sci. 2002, 59, 1945-1959. [CrossRef] [PubMed]

20. Stam, M.R.; Danchin, E.G.; Rancurel, C.; Coutinho, P.M.; Henrissat, B. Dividing the large glycoside hydrolase family 13 into subfamilies: Towards improved functional annotations of $\alpha$-amylase-related proteins. Protein Eng. Des. Sel. 2006, 19, 555-562. [CrossRef]

21. Janecek, S.; Zamocka, B. A new GH13 subfamily represented by the $\alpha$-amylase from the halophilic archaeon. Haloarcula Hisp. Extrem. 2020, 24, 207-217. [CrossRef]

22. Janecek, S.; Kuchtova, A.; Petrovicova, S. A novel GH13 subfamily of $\alpha$-amylases with a pair of tryptophans in the helix $\alpha 3$ of the catalytic TIM-barrel, the LPDlx signature in the conserved sequence region $\mathrm{V}$ and a conserved aromatic motif at the C-terminus. Biologia 2015, 70, 1284-1294. [CrossRef]

23. Sarian, F.D.; Janecek, S.; Pijning, T.; Ihsanawati; Nurachman, Z.; Radjasa, O.K.; Dijkhuizen, L.; Natalia, D.; van der Maarel, M.J.E.C. A new group of glycoside hydrolase family $13 \alpha$-amylases with an aberrant catalytic triad. Sci. Rep. 2017, 7, 44230. [CrossRef] [PubMed]

24. Janecek, S. Sequence similarities and evolutionary relationships of microbial, plant and animal $\alpha$-amylases. Eur. J. Biochem. 1994, 224, 519-524. [CrossRef]

25. Janecek, S.; Leveque, E.; Belarbi, A.; Haye, B. Close evolutionary relatedness of $\alpha$-amylases from Archaea and plants. J. Mol. Evol. 1999, 48, 421-426. [CrossRef]

26. Da Lage, J.L.; Feller, G.; Janecek, S. Horizontal gene transfer from Eukarya to bacteria and domain shuffling: The $\alpha$-amylase model. Cell. Mol. Life Sci. 2004, 61, 97-109. [CrossRef] [PubMed]

27. Majzlova, K.; Pukajova, Z.; Janecek, S. Tracing the evolution of the $\alpha$-amylase subfamily GH13_36 covering the amylolytic enzymes intermediate between oligo-1,6-glucosidases and neopullulanases. Carbohydr Res. 2013, 367, 48-57. [CrossRef]

28. van der Kaaij, R.M.; Janecek, S.; van der Maarel, M.J.E.C.; Dijkhuizen, L. Phylogenetic and biochemical characterization of a novel cluster of intracellular fungal $\alpha$-amylase enzymes. Microbiology 2007, 153, 4003-4015. [CrossRef]

29. Da Lage, J.L.; Binder, M.; Hua-Van, A.; Janecek, S.; Casane, D. Gene make-up: Rapid and massive intron gains after horizontal transfer of a bacterial $\alpha$-amylase gene to Basidiomycetes. BMC Evol. Biol. 2013, 13, 40. [CrossRef]

30. Janickova, Z.; Janecek, S. Fungal $\alpha$-amylases from three GH13 subfamilies: Their sequence-structural features and evolutionary relationships. Int. J. Biol. Macromol. 2020, 159, 763-772. [CrossRef]

31. Feller, G.; Lonhienne, T.; Deroanne, C.; Libioulle, C.; Van Beeumen, J.; Gerday, C. Purification, characterization, and nucleotide sequence of the thermolabile $\alpha$-amylase from the antarctic psychrotroph Alteromonas haloplanctis A23. J. Biol. Chem. 1992, 267, 5217-5221. [CrossRef]

32. Feller, G.; Payan, F.; Theys, F.; Qian, M.; Haser, R.; Gerday, C. Stability and structural analysis of $\alpha$-amylase from the antarctic psychrophile Alteromonas haloplanctis A23. Eur. J. Biochem. 1994, 222, 441-447. [CrossRef] [PubMed]

33. Feller, G.; Bussy, O.; Houssier, C.; Gerday, C. Structural and functional aspects of chloride binding to Alteromonas haloplanctis $\alpha$-amylase. J. Biol. Chem. 1996, 271, 23836-23841. [CrossRef]

34. Aghajari, N.; Feller, G.; Gerday, C.; Haser, R. Crystal structures of the psychrophilic $\alpha$-amylase from Alteromonas haloplanctis in its native form and complexed with an inhibitor. Protein Sci. 1998, 7, 564-572. [CrossRef] [PubMed]

35. Aghajari, N.; Feller, G.; Gerday, C.; Haser, R. Structural basis of $\alpha$-amylase activation by chloride. Protein Sci. 2002, 11, 1435-1441. [CrossRef]

36. Buisson, G.; Duee, E.; Haser, R.; Payan, F. Three dimensional structure of porcine pancreatic $\alpha$-amylase at 2.9 Å resolution. Role of calcium in structure and activity. EMBO J. 1987, 6, 3909-3916. [CrossRef] [PubMed]

37. Qian, M.; Haser, R.; Payan, F. Structure and molecular model refinement of pig pancreatic $\alpha$-amylase at $2.1 \AA$ resolution. J. Mol. Biol. 1993, 231, 785-799. [CrossRef] 
38. Brayer, G.D.; Luo, Y.; Withers, S.G. The structure of human pancreatic $\alpha$-amylase at $1.8 \AA$ A resolution and comparisons with related enzymes. Protein Sci. 1995, 4, 1730-1742. [CrossRef]

39. Ramasubbu, N.; Paloth, V.; Luo, Y.; Brayer, G.D.; Levine, M.J. Structure of human salivary $\alpha$-amylase at $1.6 \AA$ resolution: Implications for its role in the oral cavity. Acta Crystallogr. D Biol. Crystallogr. 1996, 52, 435-446. [CrossRef]

40. Strobl, S.; Maskos, K.; Betz, M.; Wiegand, G.; Huber, R.; Gomis-Rüth, F.X.; Glockshuber, R. Crystal structure of yellow meal worm $\alpha$-amylase at $1.64 \AA$ resolution. J. Mol. Biol. 1998, 278, 617-628. [CrossRef] [PubMed]

41. Qian, M.; Ajandouz, E.H.; Payan, F.; Nahoum, V. Molecular basis of the effects of chloride ion on the acid-base catalyst in the mechanism of pancreatic $\alpha$-amylase. Biochemistry 2005, 44, 3194-3201. [CrossRef]

42. D'Amico, S.; Gerday, C.; Feller, G. Structural similarities and evolutionary relationships in chloride-dependent $\alpha$-amylases. Gene 2000, 253, 95-105. [CrossRef]

43. Cockburn, D.; Wilkens, C.; Ruzanski, C.; Andersen, S.; Nielsen, J.W.; Smith, A.M.; Field, R.A.; Willemoës, M.; Hachem, M.A.; Svensson, B. Analysis of surface binding sites (SBSs) in carbohydrate active enzymes with focus on glycoside hydrolase families 13 and 77-A mini-review. Biologia 2014, 69, 705-712. [CrossRef]

44. Janecek, S.; Marecek, F.; MacGregor, E.A.; Svensson, B. Starch-binding domains as CBM families-history, occurrence, structure, function and evolution. Biotechnol. Adv. 2019, 37, 107451. [CrossRef]

45. Cockburn, D.; Nielsen, M.M.; Christiansen, C.; Andersen, J.M.; Rannes, J.B.; Blennow, A.; Svensson, B. Surface binding sites in amylase have distinct roles in recognition of starch structure motifs and degradation. Int. J. Biol. Macromol. 2015, 75, 338-345. [CrossRef] [PubMed]

46. Baroroh, U.; Yusuf, M.; Rachman, S.D.; Ishmayana, S.; Syamsunarno, M.R.A.A.; Levita, J.; Subroto, T. The importance of surfacebinding site towards starch-adsorptivity level in $\alpha$-amylase: A review on structural point of view. Enzyme Res. 2017, 2017, 4086845. [CrossRef] [PubMed]

47. Baroroh, U.; Yusuf, M.; Rachman, S.D.; Ishmayana, S.; Hasan, K.; Subroto, T. Molecular dynamics study to improve the substrate adsorption of Saccharomycopsis fibuligera R64 $\alpha$-amylase by designing a new surface binding site. Adv. Appl. Bioinform. Chem. 2019, 12, 1-13. [CrossRef]

48. Wilkens, C.; Svensson, B.; Møller, M.S. Functional roles of starch binding domains and surface binding sites in enzymes involved in starch biosynthesis. Front. Plant. Sci. 2018, 9, 1652. [CrossRef] [PubMed]

49. Vujicic-Zagar, A.; Dijkstra, B.W. Monoclinic crystal form of Aspergillus niger $\alpha$-amylase in complex with maltose at 1.8 angstroms resolution. Acta Crystallogr. Sect. F Struct. Biol. Cryst. Commun. 2006, 62, 716-721. [CrossRef]

50. Lyhne-Iversen, L.; Hobley, T.J.; Kaasgaard, S.G.; Harris, P. Structure of Bacillus halmapalus $\alpha$-amylase crystallized with and without the substrate analogue acarbose and maltose. Acta Crystallogr. Sect. F Struct. Biol. Cryst. Commun. 2006, 62, 849-854. [CrossRef]

51. Bozic, N.; Rozeboom, H.J.; Loncar, N.; Slavic, M.S.; Janssen, D.B.; Vujcic, Z. Characterization of the starch surface binding site on Bacillus paralicheniformis $\alpha$-amylase. Int. J. Biol. Macromol. 2020, 165, 1529-1539. [CrossRef]

52. Tan, T.C.; Mijts, B.N.; Swaminathan, K.; Patel, B.K.; Divne, C. Crystal structure of the polyextremophilic $\alpha$-amylase AmyB from Halothermothrix orenii: Details of a productive enzyme-substrate complex and an $\mathrm{N}$ domain with a role in binding raw starch. J. Mol. Biol. 2008, 378, 852-870. [CrossRef] [PubMed]

53. Qian, M.; Haser, R.; Payan, F. Carbohydrate binding sites in a pancreatic $\alpha$-amylase-substrate complex, derived from X-ray structure analysis at $2.1 \AA$ resolution. Protein Sci. 1995, 4, 747-755. [CrossRef]

54. Ragunath, C.; Manuel, S.G.A.; Kasinathan, C.; Ramasubbu, N. Structure-function relationships in human salivary $\alpha$-amylase: Role of aromatic residues in a secondary binding site. Biologia 2008, 63, 1028-1034. [CrossRef]

55. Pytelkova, J.; Lepsik, M.; Sanda, M.; Talacko, P.; Maresova, L.; Mares, M. Enzymatic activity and immunoreactivity of Aca s 4, an $\alpha$-amylase allergen from the storage mite Acarus siro. BMC Biochem. 2012, 13, 3. [CrossRef]

56. Mills, K.L.; Hart, B.J.; Lynch, N.R.; Thomas, W.R.; Smith, W. Molecular characterization of the group 4 house dust mite allergen from Dermatophagoides pteronyssinus and its amylase homologue from Euroglyphus maynei. Int. Arch. Allergy Immunol. 1999, 120, 100-107. [CrossRef]

57. Oliveira-Neto, O.B.; Batista, J.A.; Rigden, D.J.; Franco, O.L.; Falcao, R.; Fragoso, R.R.; Mello, L.V.; dos Santos, R.C.; Grossi-de-Sa, M.F. Molecular cloning of $\alpha$-amylases from cotton boll weevil, Anthonomus grandis and structural relations to plant inhibitors: An approach to insect resistance. J. Protein Chem. 2003, 22, 77-87. [CrossRef]

58. Yamada, T.; Ikeda, M.; Kobayashi, M.; Hattori, K. Cloning and expression of a cDNA encoding larval $\alpha$-amylase of azuki bean weevil, Callosobruchus chinensis. J. Insect Biotechnol. Sericol. 2003, 72, 139-148. [CrossRef]

59. Grossi de Sa, M.F.; Chrispeels, M.J. Molecular cloning of bruchid (Zabrotes subfasciatus) $\alpha$-amylase cDNA and interactions of the expressed enzyme with bean amylase inhibitors. Insect Biochem. Mol. Biol. 1997, 27, 271-281. [CrossRef]

60. Coronado, M.A.; Vargas, C.; Mellado, E.; Tegos, G.; Drainas, C.; Nieto, J.N.J.; Ventosa, A. The $\alpha$-amylase gene amyH of the moderate halophile Halomonas meridiana: Cloning and molecular characterization. Microbiology 2000, 146, 861-868. [CrossRef]

61. Kim, E.S.; Na, H.K.; Jhon, D.Y.; Yoo, O.J.; Chun, S.B.; Wui, I.S. Cloning, sequencing and expression of the amylase isozyme gene from Pseudomonas sp. KFCC 10818. Biotechnol. Lett. 1996, 18, 169-174. [CrossRef]

62. Yang, C.H.; Liu, W.H. Cloning and characterization of a maltotriose-producing $\alpha$-amylase gene from Thermobifida fusca. J. Ind. Microbiol. Biotechnol. 2007, 34, 325-330. [CrossRef] [PubMed]

63. Petricek, M.; Tichy, P.; Kuncova, M. Characterization of the $\alpha$-amylase-encoding gene from Thermomonospora curvata. Gene 1992, 112, 77-83. [CrossRef] 
64. Matsubara, T.; Ben Ammar, Y.; Anindyawati, T.; Yamamoto, S.; Ito, K.; Iizuka, M.; Minamiura, N. Molecular cloning and determination of the nucleotide sequence of raw starch digesting $\alpha$-amylase from Aspergillus awamori KT-11. J. Biochem. Mol. Biol. 2004, 37, 429-438. [CrossRef] [PubMed]

65. Fakhoury, A.M.; Woloshuk, C.P. Amy1, the $\alpha$-amylase gene of Aspergillus flavus: Involvement in aflatoxin biosynthesis in maize kernels. Phytopathology 1999, 89, 908-914. [CrossRef]

66. Nagamine, K.; Murashima, K.; Kato, T.; Shimoi, H.; Ito, K. Mode of $\alpha$-amylase production by the shochu koji mold Aspergillus kawachii. Biosci. Biotechnol. Biochem. 2003, 67, 2194-2202. [CrossRef]

67. Toda, H.; Kondo, K.; Narita, K. The complete amino acid sequence of Taka-amylase A. Proc. Jpn. Acad. 1982, B58, 208-212. [CrossRef]

68. Shibuya, I.; Tamura, G.; Ishikawa, T.; Hara, S. Cloning of the $\alpha$-amylase cDNA of Aspergillus shirousamii and its expression in Saccharomyces cerevisiae. Biosci. Biotechnol. Biochem. 1992, 56, 174-179. [CrossRef] [PubMed]

69. Champreda, V.; Kanokratana, P.; Sriprang, R.; Tanapongpipat, S.; Eurwilaichitr, L. Purification, biochemical characterization, and gene cloning of a new extracellular thermotolerant and glucose tolerant maltooligosaccharide-forming $\alpha$-amylase from an endophytic ascomycete Fusicoccum sp. BCC4124. Biosci. Biotechnol. Biochem. 2007, 71, 2010-2020. [CrossRef]

70. Steyn, A.J.; Marmur, J.; Pretorius, I.S. Cloning, sequence analysis and expression in yeasts of a cDNA containing a Lipomyces kononenkoae $\alpha$-amylase-encoding gene. Gene 1995, 166, 65-71. [CrossRef]

71. Kang, H.K.; Lee, J.H.; Kim, D.; Day, D.F.; Robyt, J.F.; Park, K.H.; Moon, T.W. Cloning and expression of Lipomyces starkeyi $\alpha$-amylase in Escherichia coli and determination of some of its properties. FEMS Microbiol. Lett. 2004, 233, 53-64. [CrossRef]

72. Ben Abdelmalek, I.; Urdaci, M.C.; Ben Ali, M.; Denayrolles, M.; Chaignepain, S.; Limam, F.; Bejar, S.; Marzouki, M.N. Structural investigation and homology modeling studies of native and truncated forms of $\alpha$-amylases from Sclerotinia sclerotiorum. J. Microbiol. Biotechnol. 2009, 19, 1306-1318. [CrossRef]

73. Hostinova, E.; Janecek, S.; Gasperik, J. Gene sequence, bioinformatics and enzymatic characterization of $\alpha$-amylase from Saccharomycopsis fibuligera KZ. Protein J. 2010, 29, 355-564. [CrossRef]

74. Roth, C.; Moroz, O.V.; Turkenburg, J.P.; Blagova, E.; Waterman, J.; Ariza, A.; Ming, L.; Tianqi, S.; Andersen, C.; Davies, G.J.; et al. Structural and functional characterization of three novel fungal amylases with enhanced stability and $\mathrm{pH}$ tolerance. Int. J. Mol. Sci. 2019, 20, 4902. [CrossRef] [PubMed]

75. Sorimachi, K.; Le Gal-Coëffet, M.F.; Williamson, G.; Archer, D.B.; Williamson, M.P. Solution structure of the granular starch binding domain of Aspergillus niger glucoamylase bound to $\beta$-cyclodextrin. Structure 1997, 5, 647-661. [CrossRef]

76. Janecek, S.; Sevcik, J. The evolution of starch-binding domain. FEBS Lett. 1999, 456, 119-125. [CrossRef]

77. Janecek, S.; Svensson, B.; MacGregor, E.A. Relation between domain evolution, specificity, and taxonomy of the $\alpha$-amylase family members containing a C-terminal starch-binding domain. Eur. J. Biochem. 2003, 270, 635-645. [CrossRef]

78. Lakshmi, S.A.; Shafreen, R.B.; Priyanga, A.; Shiburaj, S.; Pandian, S.K. A highly divergent $\alpha$-amylase from Streptomyces spp.: An evolutionary perspective. Int. J. Biol. Macromol. 2020, 163, 2415-2428. [CrossRef] [PubMed]

79. Lakshmi, S.A.; Shafreen, R.B.; Balaji, K.; Ibrahim, K.S.; Shiburaj, S.; Gayathri, V.; Pandian, S.K. Cloning, expression, homology modelling and molecular dynamics simulation of four domain-containing $\alpha$-amylase from Streptomyces griseus. J. Biomol. Struct. Dyn. 2021, 39, 2152-2163. [CrossRef]

80. Yuuki, T.; Nomura, T.; Tezuka, H.; Tsuboi, A.; Yamagata, H.; Tsukagoshi, N.; Udaka, S. Complete nucleotide sequence of a gene coding for heat- and $\mathrm{pH}$-stable $\alpha$-amylase of Bacillus licheniformis: Comparison of the amino acid sequences of three bacterial liquefying $\alpha$-amylases deduced from the DNA sequences. J. Biochem. 1985, 98, 1147-1156. [CrossRef]

81. Marion, C.L.; Rappleye, C.A.; Engle, J.T.; Goldman, W.E. An $\alpha-(1,4)$-amylase is essential for $\alpha$-(1,3)-glucan production and virulence in Histoplasma capsulatum. Mol. Microbiol. 2006, 62, 970-983. [CrossRef] [PubMed]

82. Camacho, E.; Sepulveda, V.E.; Goldman, W.E.; San-Blas, G.; Nino-Vega, G.A. Expression of Paracoccidioides brasiliensis AMY1 in a Histoplasma capsulatum amy1 mutant, relates an $\alpha-(1,4)$-amylase to cell wall $\alpha-(1,3)$-glucan synthesis. PLoS ONE 2012, 7, e50201. [CrossRef]

83. He, X.; Li, S.; Kaminskyj, S.G. Characterization of Aspergillus nidulans $\alpha$-glucan synthesis: Roles for two synthases and two amylases. Mol. Microbiol. 2014, 91, 579-595. [CrossRef]

84. Yoshimi, A.; Miyazawa, K.; Abe, K. Function and biosynthesis of cell wall $\alpha$-1,3-glucan in fungi. J. Fungi 2017, 3, 63. [CrossRef]

85. Miyazawa, K.; Yoshimi, A.; Kasahara, S.; Sugahara, A.; Koizumi, A.; Yano, S.; Kimura, S.; Iwata, T.; Sano, M.; Abe, K. Molecular mass and localization of $\alpha-1,3$-glucan in cell wall control the degree of hyphal aggregation in liquid culture of Aspergillus nidulans. Front. Microbiol. 2018, 9, 2623. [CrossRef] [PubMed]

86. Ramli, A.N.; Azhar, M.A.; Shamsir, M.S.; Rabu, A.; Murad, A.M.; Mahadi, N.M.; Illias, R.M. Sequence and structural investigation of a novel psychrophilic $\alpha$-amylase from Glaciozyma antarctica PI12 for cold-adaptation analysis. J. Mol. Model. 2013, 19, 3369-3383. [CrossRef] [PubMed]

87. Jones., R.A.; Jermiin, L.S.; Easteal, S.; Patel, B.K.; Beacham, I.R. Amylase and 16S rRNA genes from a hyperthermophilic archaebacterium. J. Appl. Microbiol. 1999, 86, 93-107. [CrossRef]

88. Li, C.; Du, M.; Cheng, B.; Wang, L.; Liu, X.; Ma, C.; Yang, C.; Xu, P. Close relationship of a novel Flavobacteriaceae $\alpha$-amylase with archaeal $\alpha$-amylases and good potentials for industrial applications. Biotechnol. Biofuels. 2014, 7, 18. [CrossRef] [PubMed]

89. Tagomori, B.Y.; Dos Santos, F.C.; Barbosa-Tessmann, I.P. Recombinant expression, purification, and characterization of an $\alpha$-amylase from Massilia timonae. 3 Biotech. 2021, 11, 13. [CrossRef] 
90. Yi, Z.; Fang, Y.; He, K.; Liu, D.; Luo, H.; Zhao, D.; He, H.; Jin, Y.; Zhao, H. Directly mining a fungal thermostable $\alpha$-amylase from Chinese Nong-flavor liquor starter. Microb. Cell Fact. 2018, 17, 30. [CrossRef] [PubMed]

91. Chen, L.; Yi, Z.; Fang, Y.; Jin, Y.; He, K.; Xiao, Y.; Zhao, D.; Luo, H.; He, H.; Sun, Q.; et al. Biochemical and synergistic properties of a novel $\alpha$-amylase from Chinese nong-flavor Daqu. Microb. Cell Fact. 2021, 20, 80. [CrossRef]

92. Chen, W.; Xie, T.; Shao, Y.; Chen, F. Phylogenomic relationships between amylolytic enzymes from 85 strains of fungi. PLoS ONE 2012, 7, e49679. [CrossRef]

93. Sumitani, J.; Tottori, T.; Kawaguchi, T.; Arai, M. New type of starch-binding domain: The direct repeat motif in the C-terminal region of Bacillus sp. no. $195 \alpha$-amylase contributes to starch binding and raw starch degrading. Biochem. J. 2000, 350, $477-484$. [CrossRef] [PubMed]

94. Chang, M.C.; Chang, J.C.; Chen, J.P. Cloning and nucleotide sequence of an extracellular $\alpha$-amylase gene from Aeromonas hydrophila MCC-1. J. Gen. Microbiol. 1993, 139, 3215-3223. [CrossRef] [PubMed]

95. Da Lage, J.L.; Van Wormhoudt, A.; Cariou, M.L. Diversity and evolution of the $\alpha$-amylase genes in animals. Biologia 2002, 57 (Suppl. 11), 181-189.

96. Saltzmann, K.D.; Saltzmann, K.A.; Neal, J.J.; Scharf, M.E.; Bennett, G.W. Characterization of BGTG-1, a tergal gland-secreted $\alpha$-amylase, from the German cockroach, Blattella germanica (L.). Insect Mol. Biol. 2006, 15, 425-433. [CrossRef]

97. Grossman, G.L.; Campos, Y.; Severson, D.W.; James, A.A. Evidence for two distinct members of the amylase gene family in the yellow fever mosquito, Aedes aegypti. Insect Biochem. Mol. Biol. 1997, 27, 769-781. [CrossRef]

98. Altschul, S.F.; Gish, W.; Miller, W.; Myers, E.W.; Lipman, D.J. Basic local alignment search tool. J. Mol. Biol. 1990, 215, 403-410. [CrossRef]

99. Zhu, G.; Hayashi, M.; Shimomura, N.; Yamaguchi, T.; Aimi, T. Differential expression of three $\alpha$-amylase genes from the basidiomycetous fungus Pholiota microspora. Mycoscience 2017, 58, 188-191. [CrossRef]

100. Benson, B.A.; Cavanaugh, M.; Clark, K.; Karsch-Mizrachi, I.; Ostell, J.; Pruitt, K.D.; Sayers, E.W. GenBank. Nucleic Acids Res. 2018, 46, D41-D47. [CrossRef]

101. The UniProt Consortium. UniProt: The universal protein knowledgebase. Nucleic Acids Res. 2017, 45, D158-D169. [CrossRef] [PubMed]

102. Sievers, F.; Wilm, A.; Dineen, D.; Gibson, T.J.; Karplus, K.; Li, W.; Lopez, R.; McWilliam, H.; Remmert, M.; Söding, J.; et al. Fast, scalable generation of high-quality protein multiple sequence alignments using Clustal Omega. Mol. Syst. Biol. 2011, 7, 539. [CrossRef] [PubMed]

103. Crooks, G.E.; Hon, G.; Chandonia, J.M.; Brenner, S.E. WebLogo: A sequence logo generator. Genome Res. 2004, 14, 1188-1190. [CrossRef]

104. Berman, H.M.; Westbrook, J.; Feng, Z.; Gilliland, G.; Bhat, T.N.; Weissig, H.; Shindyalov, I.N.; Bourne, P.E. The Protein Data Bank. Nucleic Acids Res. 2000, 28, 235-242. [CrossRef]

105. Jones, D.T.; Taylor, W.R.; Thornton, J.M. The rapid generation of mutation data matrices from protein sequences. Comput. Appl. Biosci. 1992, 8, 275-282. [CrossRef] [PubMed]

106. Felsenstein, J. Confidence limits on phylogenies: An approach using the bootstrap. Evolution 1985, 39, 783-791. [CrossRef] [PubMed]

107. Kumar, S.; Stecher, G.; Li, M.; Knyaz, C.; Tamura, K. MEGA X: Molecular Evolutionary Genetics Analysis across computing platforms. Mol. Biol. Evol. 2018, 35, 1547-1549. [CrossRef] [PubMed]

108. Letunic, I.; Bork, P. Interactive Tree of Life (iTOL): An online tool for phylogenetic tree display and annotation. Bioinformatics 2007, 23, 127-128. [CrossRef] 